\title{
Teaching English Discrete Sounds through Minimal Pairs
}

\author{
Luu Trong Tuan \\ National University of Ho Chi Minh City, Vietnam \\ Email: luutrongtuan@vnn.vn
}

\begin{abstract}
Minimal pairs bear great benefits in pronunciation teaching and learning which have long been of fruitful use. However, the full use of these pairs has not yet been made in the setting of Hung Vuong University. This paper sought to examine possible problems facing English non-majored students at Hung Vuong University in recognizing and producing English discrete sounds as well as in what way and to what extent do minimal pairs facilitate the teaching and learning of English discrete sounds. The data were collected both quantitatively and qualitatively from various sources: questionnaires for and interviews with both the teacher and student subjects, tests of students' sound recognitions, regular real-time observations, audio recordings of students' sound productions, and spectrogram-based analyses of these recordings. The findings revealed that virtually all of the student subjects face the six pronunciation problems: omitting the word-final consonant, adding the word-final /s/ to English words not ending in $/ \mathrm{s} /$, adding the schwa $/ 6 /$ in the middle of a consonant cluster, mispronouncing strange sounds to Vietnamese people, e.g. /t/ and /d/, failing to differentiate between long and short vowels, and failing to differentiate between voiced and voiceless consonants. Both the student and the teacher subjects also show high appreciation of the pedagogical effectiveness of minimal pairs when employed either as a teaching or learning tool within the extent to which English discrete sounds are concerned.
\end{abstract}

Index Terms—discrete sounds, minimal pairs, teaching pronunciation

\section{INTRODUCTION}

Theoretically, most educators agree that minimal pairs ${ }^{1}$ greatly facilitate students' acquisition of discrete sounds ${ }^{2}$. With their own power, minimal pair drills ${ }^{3}$ create a contrastive environment where these sounds are phonemically presented in such a way that they can be perceived with utmost ease and high motivation. Such an environment is fulfilled with contexts where a single phoneme ${ }^{4}$ functions as to denote word meaning. Contexts of this kind demonstrate the importance of pronunciation in oral communication, and thus lead students into the habit of speaking with accurate pronunciation and interpreting a spoken message with precise recognition of phonetic form of words. These facts indicate that practice with minimal pairs can naturally raise students' awareness of pronunciation and improve their production as well as recognition at word level laying the foundation for their further progress in oral skills.

In practice, communicative competence has recently been considered the first priority of most EFL teachers as well as learners. In this aspect, it is pronunciation that partially shapes the speaker's success. Actually, Celce-Murcia, Brinton and Goodwin (1996: 1) claim that "successful communication cannot take place without correct pronunciation". In other words, the pronunciation from the speaker and the recognition from the listener have great influences on the quality of communication for both of the parties. Furthermore, in his discussion about acquisition of speech sounds, Chomsky (1972: 29) states that "the person who acquired knowledge of a language has internalised a system of rules that relate sound and meaning." Accordingly, the relation between sound and meaning is so close. Nevertheless, here and there, inadequate attention is paid to pronunciation learning. The situation of the first-year students at the Hung Vuong University in Ho Chi Minh City is a good case in point. A considerable number of these English non-majored students fail to pronounce English sounds properly. Utterances in which words with similar sound forms, such as wine and wife, cannot be distinguished are of high frequency. Such mispronunciation may cause misinterpretation and potential discomfort devaluing the speaker's effort in oral communication irrespective of their fairly good stock of vocabulary and grammatical structure. Therefore, it is necessary to find a satisfactory solution to the problem, if not to put an end to the situation.

Connectedly, it is reasonable to assume that one of the first attempts to make these students fully aware of the significance of pronunciation in their second language (L2) acquisition is to distinguish English discrete sounds from

\footnotetext{
1 Minimal pairs are "pairs of words that differ in meaning on the basic of a change in only one sound." (Avery and Ehrlich, 1992: 39)

2 In the scope of this study, discrete sounds are vowels and consonants articulated separately.

3 "a DRILL in which MINIMAL PAIRS are practiced together, especially in order to help students to learn to distinguish a sound contrast" (Richards et al., 1993: 231)

4 A phoneme is "the smallest unit of sound in a language which can distinguish two words." (Richards, Platt and Weber, 1987: 214)
} 
one another by highlighting the process in which the sounds are recognized and produced first in individual words and next in phrases or isolated utterances. Using minimal pairs seems to be an appropriate tool in such a case.

Last but not least, for the sake of the student subjects' advancement of English pronunciation, the concept of Consonant Zero (CZ) was experimentally employed in the study so as to more clearly describe the problems as well as to better facilitate the experimental teaching (ET) stage.

The study was guided by the subsequent research questions:

(1)What are possible problems facing English non-majored students at Hung Vuong University in recognizing and producing English discrete sounds?

(2)In what way and to what extent do minimal pairs facilitate the teaching and learning of English discrete sounds?

(3)To what extent can the technique of teaching English discrete sounds with minimal pairs improve the students' recognition and production at word level?

(4)What are the students' attitudes towards the technique?

\section{LITERATURE REVIEW}

\section{A. Minimal Pairs}

Minimal pairs have been defined in various ways.

(1) Minimal pairs are "pairs of words that differ in meaning on the basis of a change in only one sound." (Avery and Ehrlich, 1995: 39)

(2) "A first rule of thumb to determine the phones of any language is to see whether substituting one sound for other results in a different word. If it does, the two sounds represent different phones. When two different forms are identical in every way except for one sound segment that occurs in the same place in the string, the two words are called a minimal pairs." (Fromkin and Rodman, 1993: 218)

(3) "A minimal pair consists of two words pronounced alike except for a single phonemic difference. A phoneme is the smallest unit of significantly distinctive sound. The phonemic difference is responsible for radical changes in the meaning of the word, as in hat-hit or thing-sing. Consequently, errors in auditory discrimination and/or articulation of these sounds may result in misunderstanding and misinterpretations of the meaning of the word, phrase or sentence." (Nilsen and Nilsen, 1973: 15)

\section{B. Relationship between Minimal Pairs and Pronunciation Acquisition}

When properly employed, minimal pairs effectively facilitate pronunciation acquisition. The good cases in point are lessons and exercises designed by Baker (2006a; 2006b) in the two textbooks entitled Tree or Three and Sheep or Ship; and by Baker \& Goldstein (2008) in the textbook entitled Pronunciation Pairs. These two authors share and illustrate the view that "language teachers can improve their students' pronunciation markedly drilling minimal pairs in order to help them improve their intelligibility" (Hansen, 1995: 36). When learners compare and contrast discrete sounds in the environment presented in minimal pairs, the importance of these sounds in denoting word meaning is transferred to their mind naturally. Experience shows that "pronunciation classes... make students more conscious of their own pronunciation and aware of ways in which their pronunciation differs from the model offered" (Rajadurai, 2001: 14). Only when seeing this difference, will Vietnamese learners of English find out the importance of discrete sounds in the English language and that of the tone ${ }^{5}$ in the Vietnamese language are of equal value in denoting word meaning. Accordingly, this finding will raise Vietnamese learners' awareness of accurate pronunciation when speaking English. This may also help lay the foundation for further progress in such aspects of connected speech as linking, elision and assimilation.

\section{Relevant Researches and Theories}

\section{Relevant researches}

Using minimal pairs to teach pronunciation has long been an interesting topic. A great number of researchers have spent their time and energy to exploit the advantages of this technique. Among these studies, the following are believed to have the closest relation with this research.

First, the research entitled Recognizing Words in Continuous Speech: how important are word-final consonants was conducted by Tauroza (1993), a senior lecturer of English, with the participation of learners from Hong Kong, Italy and

\footnotetext{
${ }^{5}$ Tone is "the height of pitch and change of pitch which is associated with the pronunciation of syllables or words and which affects the meaning of the word." In Vietnamese, which is a tone language, tone is used to differentiate words; i.e. variations in pitch affect the meaning of words and thus, substituting one distinctive tone for another on a particular word or morpheme can cause a change in the lexical meaning of that word or morpheme: - $\mathrm{ma}$ (with the mid-level tone $)=$ ghost

- má (with the high-rising tone) $=$ cheek, mother

- mà (with the low-falling tone) = but

- mạ (with the low-broken tone $)=$ rice seeding

- mả (with the low-rising tone $)=$ tomb

- mã (with the high-broken tone) = horse

In English, which is an intonation language, "tone does not differentiate words in this way. Instead, it operates above the level of words and is perceived to influence the meaning of chunks of speech, which are commonly called tone units." (Richards et al., 1993: 382)
} 
the UK as its student subjects to find out at what level word-final consonants affect word recognition. This paper employs minimal pairs as part of the instrument used. The finding indicates that the instability of word-final consonants in spoken English is regarded as a potential problem for listeners, especially those who are L2 listeners.

Second, the research titled Teaching Pronunciation with Minimal Pairs conducted by Mora (2004), Associate Professor at San Diego State University mainly proves that, together with flashcards and matching items, minimal pairs can be used to effectively enhance students' pronunciation and recognition at word level.

2. Relevant theories of pronunciation teaching

The following review of relevant theory bases itself mostly on descriptions of approaches and techniques for pronunciation teaching reviewed by Avery and Ehrlich (1995) and Celce-Murcia et al. (1996).

An intuitive-imitative approach depends on the learner's ability to listen and to imitate the rhythms and sounds of the target language without the intervention of any explicit information. It also presupposes the availability of good models to listen to, a possibility that has been enhanced by the availability first of phonograph records, then of tape recorders and language labs in the mid-twenty century and more recently of audio and video cassettes and compact discs.

An analytic-linguistic approach utilizes contrastive information and tools such as charts of the vocal tract, descriptions of articulators and of the target sound system, etc. and other aids to supplement listening, imitation, and production. It explicitly informs the learner of and focuses attention on the sounds and rhythms of the target language. This approach was developed to complement rather than to replace the intuitive-imitative approach, which was typically retained as the practice phase used in tandem with the phonetic information.

The Direct Method allows the teaching of pronunciation through intuition and imitation: students imitate a model the teacher or a recording - and do their best to approximate the model through imitation and repetition. This instructional method was grounded on observations of children learning their first language and of children and adults learning foreign languages in non-instructional settings.

Naturalistic methods mostly expose students to listening before any speaking. Examples include Asher's (1977) Total Physical Response and Krashen and Terrell's (1983) Natural Approach. Proponents maintain that the initial focus on listening without pressure to speak gives the learner the opportunity to internalize the target sound system. When the learner does speak later on, their pronunciation is supposedly quite good despite their never having received explicit pronunciation instruction.

The Reform Movement advocates the following notions of practice:

-The spoken form of a language is primary and should be taught first;

-The findings of phonetics should be applied to language teaching;

-Teachers must have solid training in phonetics;

-Learners should be given phonetic training to establish good speech habits.

The Audio-lingual and Oral Approach sees pronunciation very important and thus taught explicitly from the start. As in the Direct Method classroom, the teacher (or a recording) models a sound, a word, or an utterance and the learner imitate or repeat. However, the teacher also typically makes use of information from phonetics and/or visual aids that demonstrate the articulation of sounds. Furthermore, the teacher often uses minimal pair drills, a technique derived from the notion of contrast in structural linguistics.

The Silent Way emphasizes pronunciation accuracy of the sounds of the target language from the very initial stage, enabling the learner to sharpen their own inner criteria for accurate production. In the Silent Way, the learner's attention is focused on the production of the sound system without having to learn the phonetic alphabet or a body of explicit linguistic information. The teacher speaks as little as possible, indicating through gestures what the learner should do. This includes an elaborate system in which the teacher tap out rhythmic patterns with a pointer, hold up their fingers to indicate the number of syllables in a word or to indicate stressed elements, or model proper positioning of the articulators by pointing to their own lips, teeth, or jaw.

The Communicative Approach sees using language to communicate as central in all classroom language instruction because the primary purpose of language is communication. This focus on language as communication brings renewed urgency to the teaching of pronunciation, for both empirical and anecdotal evidence indicates that there is a threshold level of pronunciation for nonnative speakers of English: if they fall below this threshold level, they will have oral communication problems no matter how excellent and extensive their control of English grammar and vocabulary might be.

\section{RESEARCH METHODOLOGY}

\section{A. Participants}

The study was carried out with the involvement of fifty-four first-year students from Class 2010A who major in tourism and all of the twenty teachers of English from the English Department at Hung Vuong University.

\section{B. Materials and Instruments}

In order to accomplish the research project, the researcher made proper use of:

1. Technological tools

Teaching tools 
Three application softwares designed for learning English pronunciation:

Pronunciation Power 1 and Pronunciation Power 2 (abbreviated to ProPowerl and ProPower2 respectively) published by English Computerized Learning Inc. (see Figure 1)
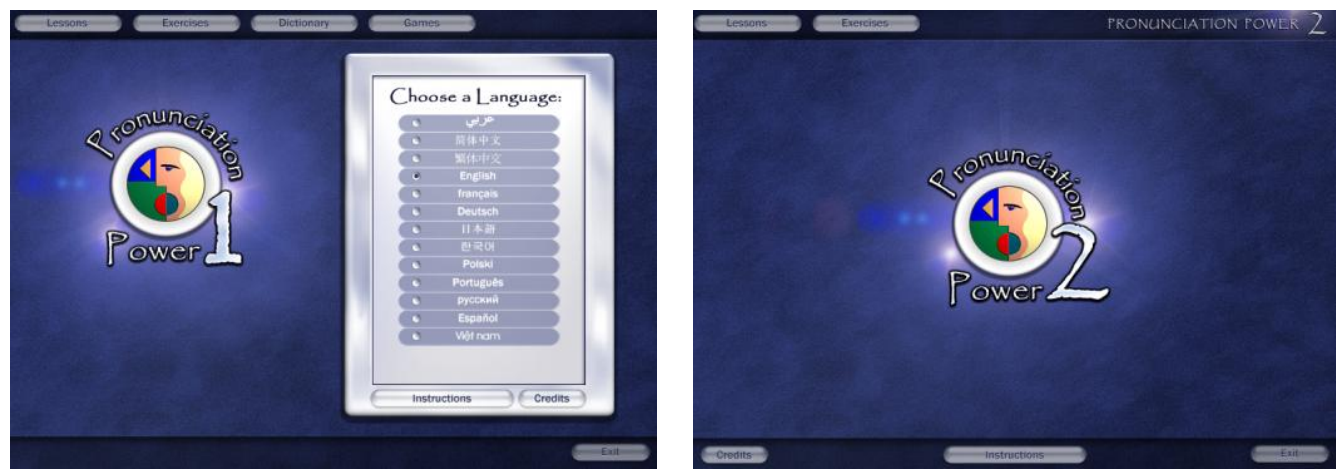

Figure 1: Interfaces of ProPowerl and ProPower2

Two selected features of these softwares, which are used in ET, are Lessons and Exercises.

Lessons provides the learner with audiovisual descriptions of all English speech sounds from which the learner can choose a particular sound to study (see Figure 2).

\begin{tabular}{|c|c|c|c|c|c|c|c|c|}
\hline \multicolumn{3}{|c|}{ Vowel sounds } & \multicolumn{6}{|c|}{ Consonant sounds } \\
\hline 1 & iy & $\overline{b e r t}$ & 19 & $\mathbf{p}$ & pack & 37 & $\mathbf{h}$ & hack \\
\hline 2 & I & bt & 20 & b & back & 38 & d3 & ump \\
\hline 3 & ey & b.it & 21 & $\mathbf{t}$ & tank & 39 & $\mathbf{t S}$ & shum \\
\hline 4 & $\mathbf{E}$ & bet & 22 & d & dad & 40 & す & that \\
\hline 5 & $\mathbf{a}$ & b.t & 23 & $\mathbf{k}$ & cap & 41 & $\boldsymbol{\theta}$ & thank \\
\hline 6 & $\mathbf{a}$ & bit & 24 & $\mathbf{9}$ & $9 a$ & \multirow{2}{*}{\multicolumn{3}{|c|}{ Cluster sounds }} \\
\hline 7 & $u^{w}$ & $p 001$ & 25 & $\mathbf{m}$ & man & & & \\
\hline 8 & $\mathbf{U}$ & book & 26 & $\mathbf{n}$ & new & 42 & $\boldsymbol{\theta r}$ & three \\
\hline 9 & $\mathbf{O}^{\mathbf{w}}$ & boat & 27 & J & hang & 43 & $\mathbf{k w}$ & quack \\
\hline 10 & 5 & pot & 28 & $f$ & fat & 44 & sp & spend \\
\hline 11 & ay & bite & 29 & $\mathbf{v}$ & yest & 45 & sk & sky \\
\hline 12 & oy & boil & 30 & $I$ & love & 46 & st & nest \\
\hline 13 & $a^{m}$ & plow & 31 & $\mathbf{r}$ & run & 47 & Id & mold \\
\hline 14 & $\mathbf{y}$ & yam & 32 & $\mathbf{w}$ & $m / n$ & 48 & It & belt \\
\hline 15 & ar & work & 33 & $z$ & 700 & 49 & fs & laughs \\
\hline 16 & or & storm & 34 & $\mathbf{s}$ & sat & 50 & ks & masks \\
\hline 17 & ar & hard & 35 & 3 & pleasure & 51 & ts & lasts \\
\hline 18 & ir & fear & 36 & $\mathbf{S}$ & shin & 52 & nz & hands. \\
\hline
\end{tabular}

Figure 2: List of sounds from Lessons in ProPower1 and ProPower2

-Side View and Front View depict both "inner workings" and "outer workings" of the vocal tract during articulation. Also included in both of the softwares is Air Flow Legend, which lists major air flow qualities including voicing, obstruction and release, replicated when activating the Side View video (see Figure 3).

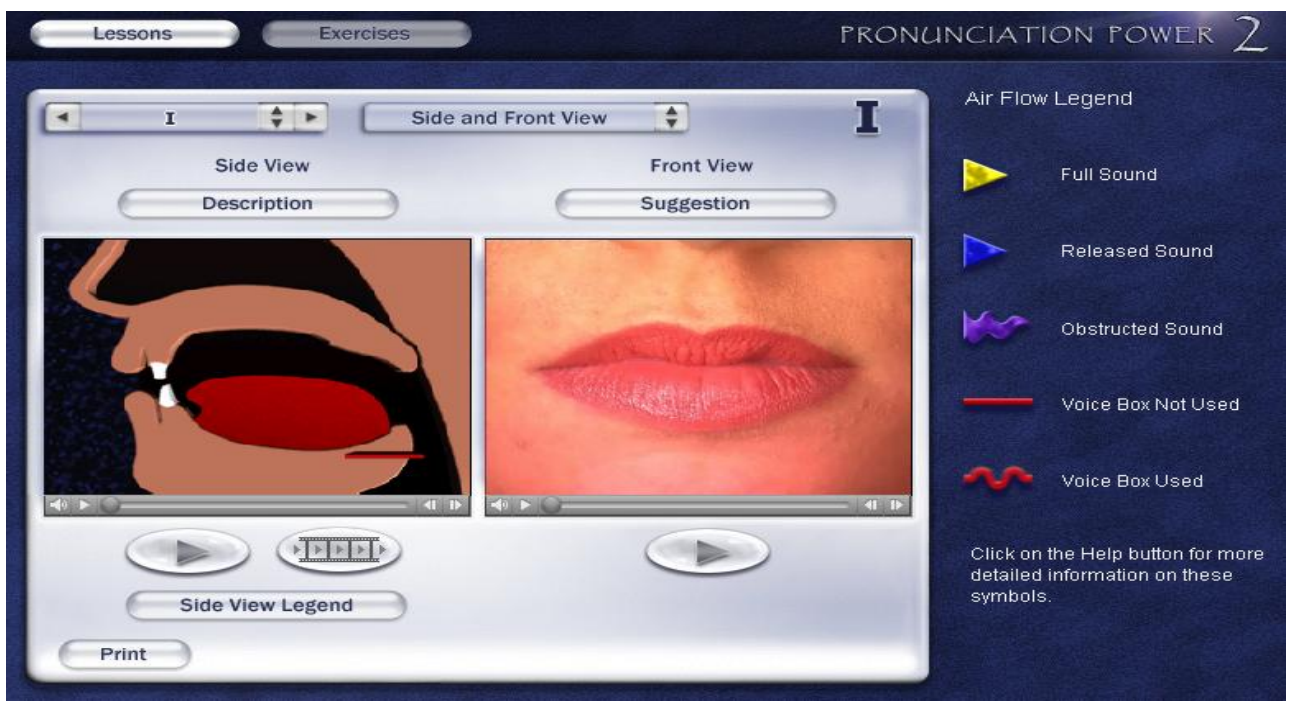

Figure 3: Side View, Front View and Air Flow Legend as observed in ProPower2 
-Side View Legend (available only in ProPower2) visualizes the articulators and their positions (see Figure 4).

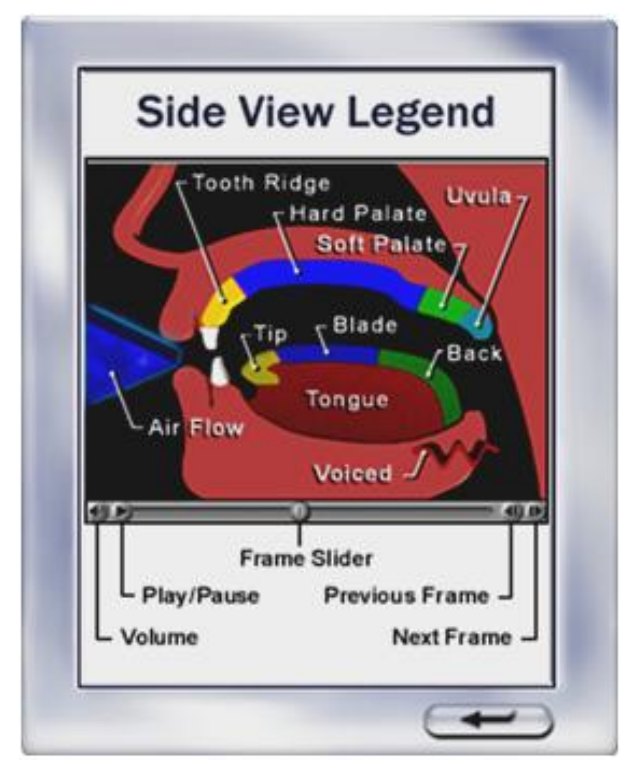

Figure 4: Side View Legend as observed in ProPower2

-Description (available only in ProPower2) tells the learner how to "operate" the articulators when pronouncing a particular sound (see Figure 5).

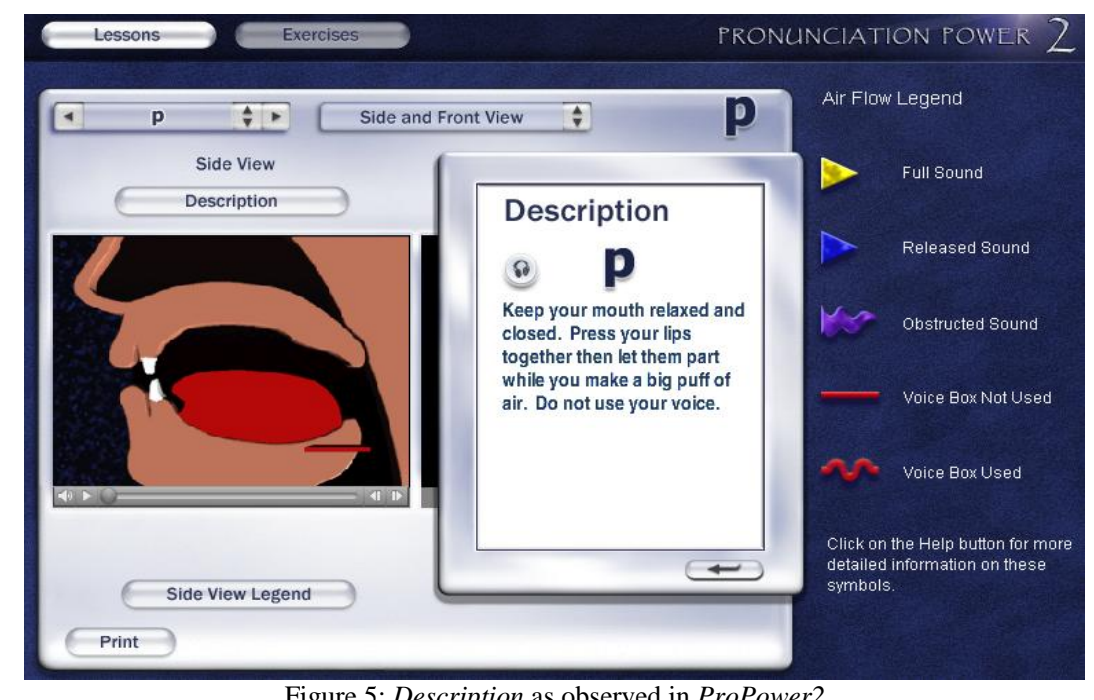

-Suggestion (available only in ProPower2) offers the learner particular tips for the production of particular sounds (see Figure 6).

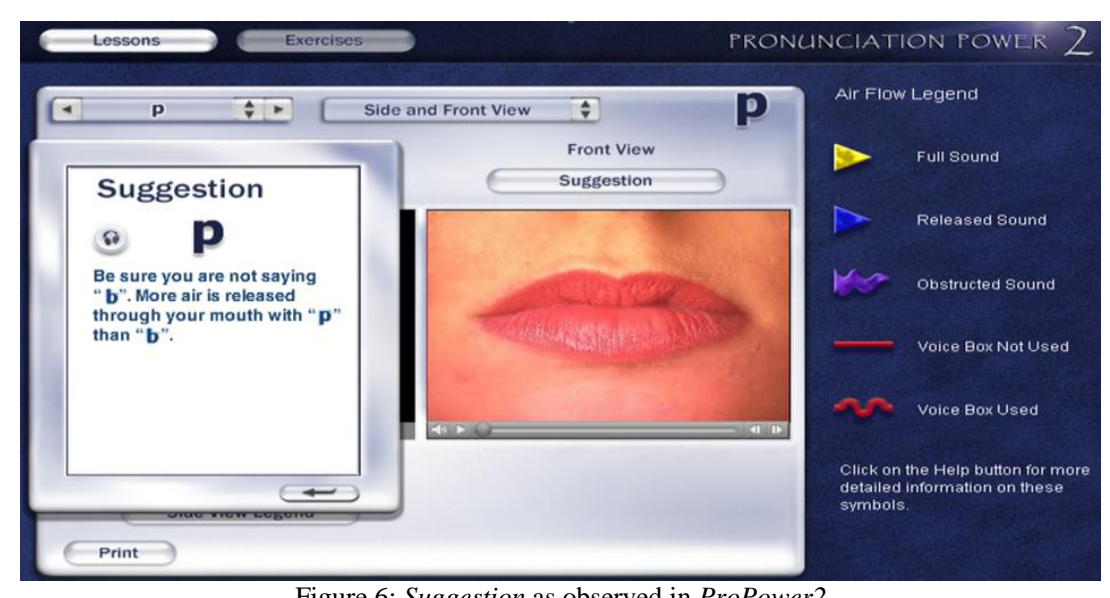

Figure 6: Suggestion as observed in ProPower2 
-Description and Suggestion available in ProPower 2 are well suited to the experimental teaching because they are really simplified instructions which can make special impression of student acquisition of the sounds.

Exercises is a collection of various kinds of pronunciation exercises, only three of which are used in ET - Sample Words, Comparative Words, and Listening Discrimination. This choice was based on their directness to teaching technique (see Figure 7).

\begin{tabular}{|c|c|c|c|c|c|c|}
\hline \multicolumn{3}{|c|}{ Sample Words } & \multicolumn{3}{|c|}{ Comparative Words } & Listening Discrimination \\
\hline iv $\$ 1$ & ple words i & & & Comparative wor & ty & I. Listening Discrimination \\
\hline (8) eel & (8) need & (8) $\mathrm{m}$ & 8 & fill - feel & (8) hit - height & (8) I really like the red tint/tent. \\
\hline (8) easy & (8) cheese & 8 or & 8 & wish - wash & (8) still - steel & (8) The last lemon we used was better/bitter. \\
\hline (8) eventually & (8) unique & (8) $\mathrm{sh}$ & 8 & chip - cheap & 8 lids - leads & (8) Her mother told her not to hit/hate her. \\
\hline (8) enough & (8) complete & (8) er & 8 & hill - hell & 8) live - leave & (8) His lips/leaps draw a lot of attention. \\
\hline (8) efficient & (8) piece & $80 \mathrm{hi}$ & 8 & women - woman & (8) rid-raid & (8) We couldn't believe the farmer's grain/gri \\
\hline
\end{tabular}

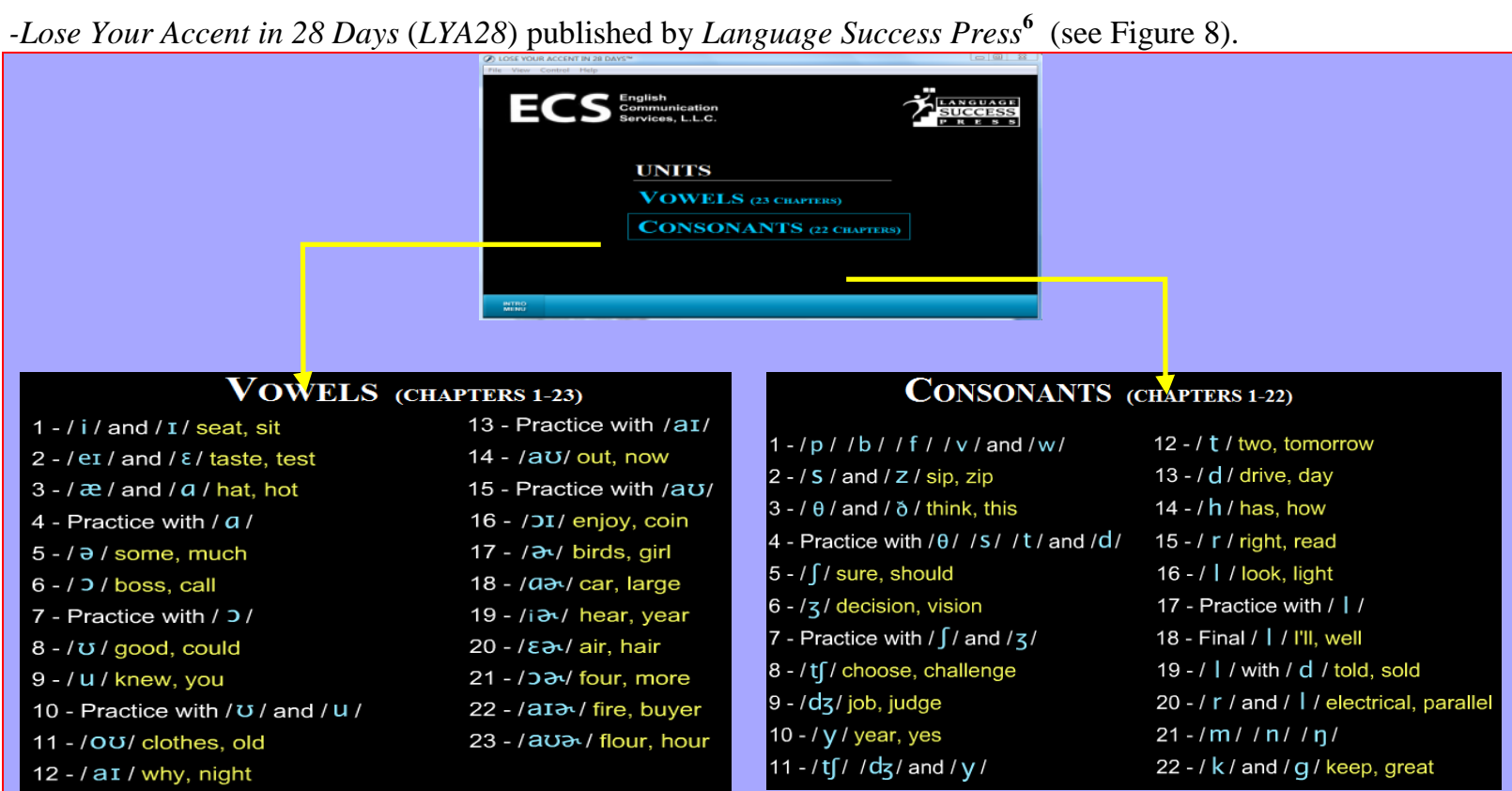

Figure 8: Interfaces of LYA28

LYA28 seems to be a perfect addition to ProPower2: while LYA28 provides video clips of sample words and an utterance in which a relevant minimal pair is employed (see Figure 9), ProPower 2 only gives those of discrete sounds.

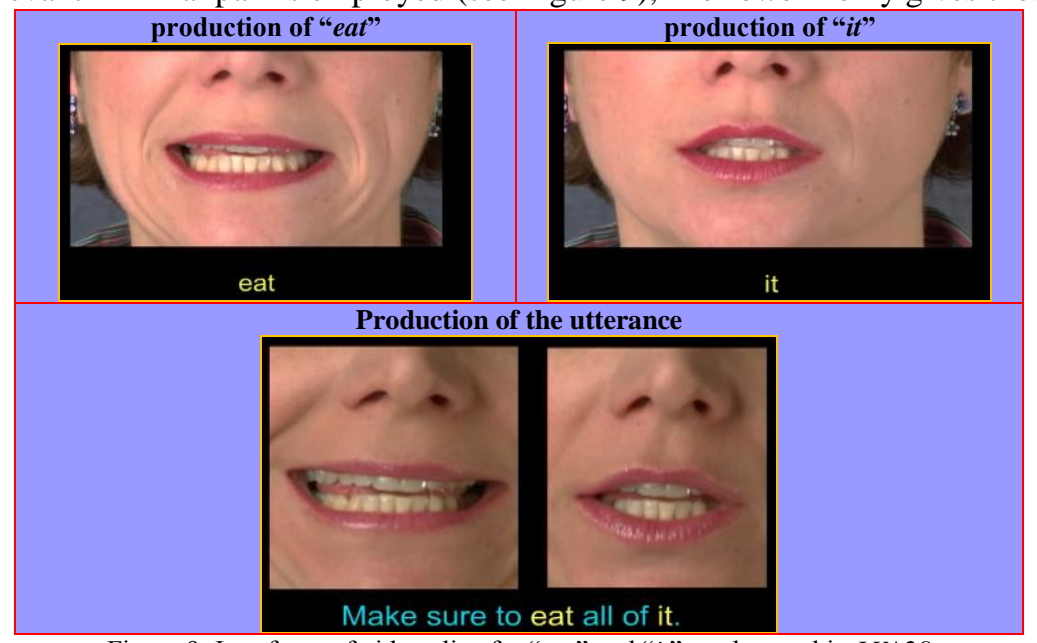

Figure 9: Interfaces of video clips for "eat" and " $i t$ " as observed in $L Y A 28$

\footnotetext{
${ }^{6}$ a core part of the complete pronunciation syllabus composed by Judy Ravin, the CEO of English Communication Services (ECS), LLC, a reduction training company; and published by Language Success Press, whose website can be accessed at http://www.lessaccent.com
} 


\section{Recording tool}

One application software named All Audio Recorder - Version 2.10 produced by Microsoft Corporation serves as the sound recording tool during the research project. Its interface looks like Figure 10.

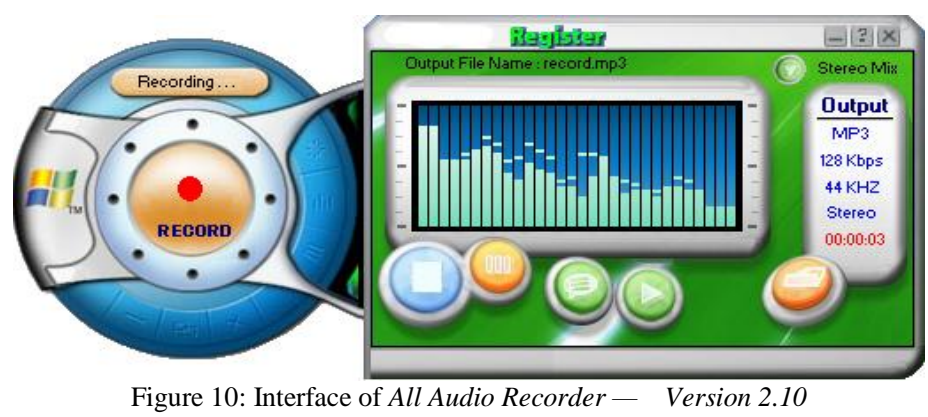

\section{Analysing tool}

Praat - Version 4.6.06 published by University of Amsterdam ${ }^{7}$ is employed for acoustic analysis. Its full interface of a spectrogram describing a sound looks like Figure 11.

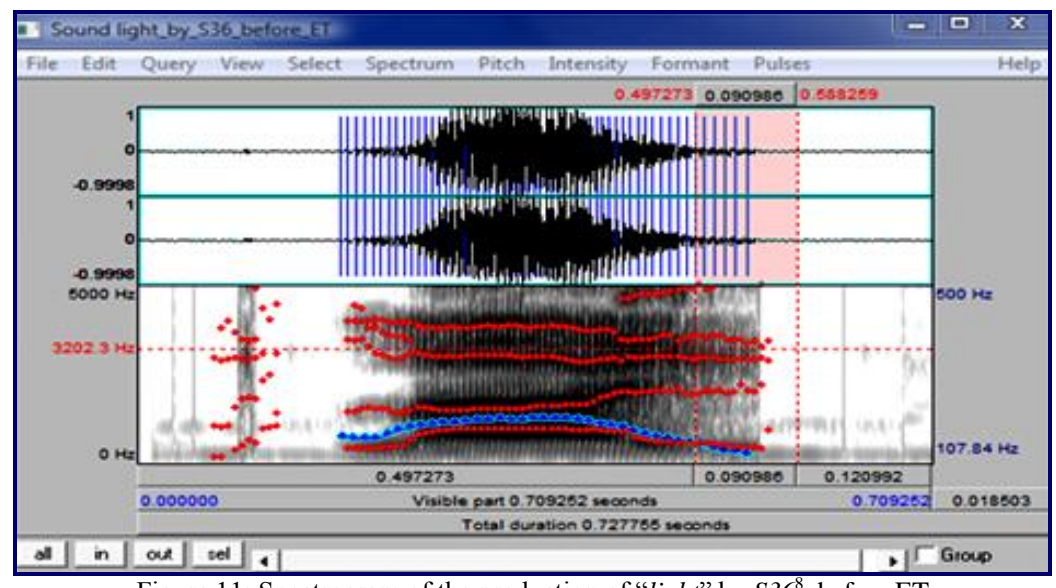

Figure 11: Spectrogram of the production of "light" by $S 36^{8}$ before ET

In this spectrogram, there are two parts: the upper is the waveform and the lower is the formant-form of the sound analysed. Darker parts of the spectrogram mean higher energy densities while lighter parts of the spectrogram mean lower energy densities. The vertical red dotted lines function as dividers ${ }^{9}$ which allow any selected part of the sound to be played.

To see what time and frequency a certain part of the spectrogram is associated with, just click on the spectrogram and you will see the vertical time cursor showing the time above the waveform and the horizontal frequency cursor showing the frequency to the left of the spectrogram. This is one of the ways to find the formant frequencies for vowels, or the main spectral peaks for fricatives.

The study's analyses do not go so deep into the phonetic characteristics of the sounds. Instead, only the waveform of the sound is analyzed due to the fact that the analyses of the sounds recorded aim at whether the pronunciation of a given individual word contains the productions of all its phonemic elements or whether a sound is voiced or voiceless. In other words, not the "full face" of the spectrogram but its waveform is presented in the analysis of the recordings. That is to say, the spectrogram of a sound analysed will become like Figure 12.

\footnotetext{
${ }^{7}$ Praat, which is a free application software program for the analysis of speech in phonetics, has been designed and continuously developed by Paul Boersma and David Weenink from the Institute of Phonetic Sciences, University of Amsterdam. This software can be downloaded at http://www.fon.hum.uva.nl/praat/.

${ }^{8}$ is the short form of "Student numbered 36 "

${ }^{9}$ The positions of these dividers are adjusted this way: point the cursor to the desired location and then left-click the mouse to locate the first divider; left-click on this first divider and drag to the desired location then drop it to locate the second divider. The first horizontal line right below the formant part is also divided into the same proportions. The selected part of the sound is played when the responding part in this line is left-clicked. The whole sound is played when either the second or the third horizontal line below the formant-form is left-clicked.
} 


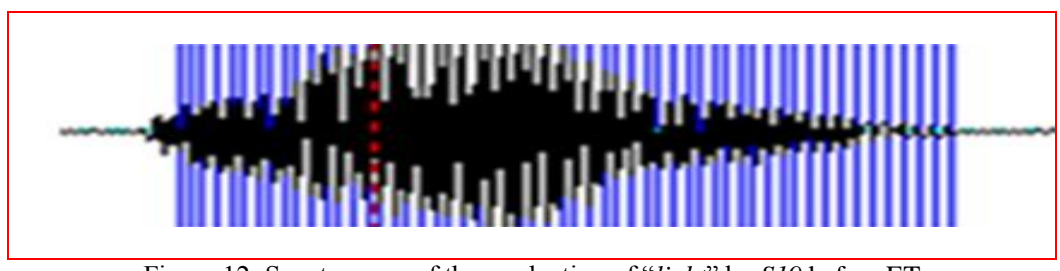

Figure 12: Spectrogram of the production of “light" by S19 before ET

\section{Pronunciation test}

One pronunciation test was designed by the researcher which serves as both Diagnostic Test ${ }^{\mathbf{1 0}}$ given at the pre-experimental teaching stage and Achievement Test ${ }^{11}$ given at the post-experimental teaching stage. This test script was read and recorded by a native speaker of English. With its four parts each of which contains five questions, the test is intended to check the students' recognition of English discrete sounds presented in the scope of individual words, phrases and short utterances. These four parts present the sounds to be tested in different environments where their conveying minimal pairs are included with the difficulty levels ranged from least to most.

The test is used twice because of the fact that two different tests cannot perform the same testability no matter how carefully they are designed. Consequently, the results of the two different tests may not be an adequately reliable base for assessing the students' achievement. Furthermore, collecting the test papers right after they are finished can minimize the test takers' memory of the items tested. Last but not least, the interval between the two tests (nine weeks) is also believed to be long enough for the student subjects to "empty" their memory of what they have been tested.

3. Recordings

Recordings of the students' production are carried out at two different times: before and after experimental teaching, thus named Pre-experiment Recordings and Post-experiment Recordings, each consisting of fifty-four students' recordings. The comparison of Pre-experiment Recordings and Post-experiment Recordings is expected to validate the diagnosis of the problems facing the student subjects when they deal with English discrete sounds as well as their progress after experimental teaching.

For further assessment of students' production, additional recordings of a number of individual words produced by a native teacher of English were also conducted to serve as the "standard spectrograms" on which the analyses of the students' productions of the same sounds were based.

4. Questionnaires

Three sets of questionnaires were designed for the study: one for the teacher subjects, the remaining two are for the student subjects. The two sets of students' questionnaires were written in Vietnamese so that the students could fully understand the questions and precisely express their viewpoints.

- Students' Questionnaire 1 is composed of nine questions which aim at gathering the subjects' background in English learning before the experimental teaching viz English learning history, attitudes towards English pronunciation, methods for learning pronunciation, and awareness of pronunciation in oral communication.

- Students' Questionnaire 2 is made up of eight questions the first six of which are supposed to evaluate the subjects' awareness of and attitudes to learning pronunciation with minimal pairs. The remaining two questions provide the chance for the students to state their difficulties in learning pronunciation and suggestions of how to overcome such difficulties.

- Teachers' Questionnaire consists of twelve questions which are distributed in three parts: Part 1 (questions 1 through 3) is intended to investigate the subjects' opinion on teaching discrete sounds by means of minimal pairs; Part 2 (questions 4 to 9) focuses on particular items related to this teaching technique, namely classroom activities, exercises, common troublesome sounds, sources of minimal pairs and the designing, time spent, and so on; Part 3 (questions 10 to 12) aims at the subjects' comments on and further recommendations for the teaching technique.

5. Interviews

A numbers of face-to-face interviews with a number of teachers and students carried out in case of need for extra qualitative information. These interviews help fulfill the gaps which may be left unstated due to the limited scope of the three sets questionnaires or any other reason.

\section{Observations}

Observations done by the researcher during the whole process of the experimental teaching presumably lasts nine forty-five-minute periods, one per week.

\section{FINDINGS AND DISCUSSION}

\section{A. Results from Questionnaire Surveys}

\section{Results from Students' Questionnaire 1}

\footnotetext{
${ }^{10} \mathrm{~A}$ diagnostic test "is designed to show what skills or knowledge a learner knows and doesn't know." (Richards et al., 1993: 106)

${ }^{11}$ An achievement test "measures how much of a language someone has learned with reference to a particular course of study or programme of instruction." (Richards et al., 1993: 3)
} 
Question 1 collects information about the total length of the students' exposure to English.

TABLE 1:

STUDENTS' TIME FOR LEARNING ENGLISH

\begin{tabular}{|c|c|c|c|c|c|}
\hline & & Frequency & Percent & Valid Percent & Cumulative Percent \\
\hline \multirow{4}{*}{ Valid } & 7 years & 39 & 72.2 & 72.2 & 72.2 \\
\hline & 3 years & 12 & 22.2 & 22.2 & 94.4 \\
\hline & Less than 3 years & 3 & 5.6 & 5.6 & 100.0 \\
\hline & Total & 54 & 100.0 & 100.0 & 100.0 \\
\hline
\end{tabular}

As shown in Table 1, most of the students have studied English for a long time, having seven-year experience in English learning. Most of the remaining has studied English for three years. There are only a few cases of less than three years. This fact originates from the division of the English programme in the Vietnamese high school system into two: the seven-year and the three-year. The cases of less than three years result from some interruptions or switches of the programs applied in some local schools.

Question 2 investigates the students' self-evaluation of their pronunciation before ET.

TABLE 2:

STUDENTS' SELF-EVALUATION OF THEIR PRONUNCIATION BEFORE ET

\begin{tabular}{|c|c|c|c|c|c|}
\cline { 3 - 5 } \multicolumn{2}{c|}{} & Frequency & Percent & Valid Percent & Cumulative Percent \\
\hline \multirow{3}{*}{ Valid } & Good & 6 & 11.1 & 11.1 & 11.1 \\
\cline { 2 - 6 } & Not very good & 34 & 63.0 & 63.0 & 74.1 \\
\cline { 2 - 6 } & Bad & 14 & 25.9 & 25.9 & 100.0 \\
\cline { 2 - 5 } & Total & 54 & 100.0 & 100.0 & 100.0 \\
\hline
\end{tabular}

Approximately two thirds $(63 \%)$ of the students evaluate themselves as not very good; approximately a quarter (25.9\%) as bad; only a little more than one-tenth (11\%) think their pronunciation of English is good enough; and none of the students consider themselves excellent in this aspect (see Table 2). That means most of the students do not have enough confidence in English pronunciation; accordingly, more support is needed.

Question 3 focuses on the students' awareness of pronunciation before experimental teaching.

TABLE 3:

\begin{tabular}{|c|c|c|c|c|c|}
\multicolumn{2}{c|}{ STUDENTS' AWARENESS OF PRONUNCIATION BEFORE ET } \\
\cline { 2 - 6 } & \multirow{2}{*}{ Frequency } & Percent & Valid Percent & \multirow{2}{*}{ Cumulative Percent } \\
\hline \multirow{4}{*}{ Valid } & Very important & 25 & 46.3 & 46.3 & 46.3 \\
\cline { 2 - 6 } & Important & 20 & 37.0 & 37.0 & 83.3 \\
\cline { 2 - 6 } & Not very important & 5 & 9.3 & 9.3 & 92.6 \\
\cline { 2 - 6 } & Not important at all & 4 & 7.4 & 7.4 & 100.0 \\
\cline { 2 - 6 } & Total & 54 & 100.0 & 100.0 & 100.0 \\
\hline
\end{tabular}

Nearly half of the students $(46.3 \%)$ believe that pronunciation is very important in oral communication; more than one-third (37.0\%) think it is important; only a small proportion $(7.4 \%)$ have little or no attention of the significance of pronunciation (see Table 3). Connectedly, it is obvious that the majority of the students are highly aware of the essentiality of pronunciation in oral communication.

Question 4 finds out the students' frequency of practising pronunciation before ET.

TABLE 4:

STUDENTS' FREQUENCY OF PRACTISING PRONUNCIATION BEFORE ET

\begin{tabular}{|c|c|c|c|c|c|}
\hline & & Frequency & Percent & Valid Percent & Cumulative Percent \\
\hline \multirow{4}{*}{ Valid } & Very often & 6 & 11.1 & 11.1 & 11.1 \\
\hline & Often & 36 & 66.7 & 66.7 & 77.8 \\
\hline & Sometimes & 12 & 22.2 & 22.2 & 100.0 \\
\hline & Never & 54 & 100.0 & 100.0 & 100.0 \\
\hline
\end{tabular}

As displayed in the Table 4 , none of the students $(0.0 \%)$ practise pronunciation frequently, nearly a quarter $(22.2 \%)$ never did this themselves, two-thirds $(66.7 \%)$ spent only a little time on this, and only one-tenth $(11.1 \%)$ had adequate practice of pronunciation. That leads to the fact that most of the students did not practice English pronunciation adequately which contradicts their adequate awareness of the issue reflected in their responses to Question 3. Such contradiction led to some interviews with the students to get some satisfactory explanation being reported later in the analysis of the interviews.

Question 5 indentifies the students' expected use of English in the future. 
TABLE 5:

STUDENTS' EXPECTED USE OF ENGLISH IN THE FUTURE

\begin{tabular}{|c|c|c|c|c|c|}
\cline { 3 - 5 } \multicolumn{1}{c|}{} & Frequency & Percent & Valid Percent & Cumulative Percent \\
\hline \multirow{4}{*}{ Valid } & Very much & 16 & 29.6 & 29.6 & 29.6 \\
\cline { 2 - 6 } & Much & 28 & 51.9 & 51.9 & 81.5 \\
\cline { 2 - 6 } & Not much & 10 & 18.5 & 18.5 & 100.0 \\
\cline { 2 - 6 } & Total & 54 & 100.0 & 100.0 & 100.0 \\
\hline
\end{tabular}

More than three quarters of the students $(81.5 \%)$ predict that they will use English at high level in their future job. Only a few (18.5\%) think that English will not be of great use to their future career (see Table 5). None of the students think that English is of no use in their future jobs. This fact suggests that most of the students know that English plays an important role in their future career.

Question 6 finds out how much time a day the students spend on self-studying English.

TABLE 6:

STUDENTS’ TIME SPENT ON LEARNING ENGLISH PER DAY

\begin{tabular}{|c|c|c|c|c|c|}
\multicolumn{2}{c|}{} & \multicolumn{2}{c}{ STUDENTS' TIME SPENT ON LEARNING ENGLISH PER DAY } \\
\cline { 2 - 6 } & Frequency & Percent & Valid Percent & Cumulative Percent \\
\hline \multirow{4}{*}{ Valid } & Half an hour & 10 & 18.5 & 18.5 & 18.5 \\
\cline { 2 - 6 } & 1 hour & 32 & 59.3 & 59.3 & 77.8 \\
\cline { 2 - 6 } & 2 hours & 8 & 14.8 & 14.8 & 92.6 \\
\cline { 2 - 6 } & More than 2 hours & 4 & 7.4 & 7.4 & 100.0 \\
\cline { 2 - 6 } & Total & 54 & 100.0 & 100.0 & 100.0 \\
\hline
\end{tabular}

Table 6 shows more than three quarters of the students (81.5\%) spending over one hour learning English a day. That is quite a big amount of time because the students have, on average, five "hours-off-campus" a day. Thus, there arises a wonder why they spend little time improving their pronunciation as reflected in the results of Question 4 . Further explanation of this inconsistency will later be discussed in the analysis of the interviews with the students.

Question 7 helps to confirm whether the students' previous teachers of English really taught pronunciation to them in class. All of the students said that the teachers did. Regarding the responses to the previous questions, there is some incongruity which requires more information about this issue.

Question 8 collects additional information about the frequency of pronunciation teaching to the students by their previous teachers.

TABLE 7:

PREVIOUS TEACHERS' PRONUNCIATION TEACHING

\begin{tabular}{|c|c|c|c|c|c|}
\cline { 3 - 5 } \multicolumn{2}{c|}{} & Frequency & Percent & Valid Percent & Cumulative Percent \\
\hline \multirow{5}{*}{ Valid } & In every class & 4 & 7.4 & 7.4 & 7.4 \\
\cline { 2 - 6 } & Often & 16 & 29.6 & 29.6 & 37.0 \\
\cline { 2 - 6 } & Sometimes & 20 & 37.0 & 37.0 & 74.1 \\
\cline { 2 - 6 } & Seldom & 14 & 25.9 & 25.9 & 100.0 \\
\cline { 2 - 6 } & Total & 54 & 100.0 & 100.0 & 100.0 \\
\hline
\end{tabular}

At different levels of frequency - 7.\% always, $29.6 \%$ often, $37 \%$ sometimes and $25.9 \%$ seldom - but all their previous teachers did teach pronunciation to the students during the years at school (see Table 7). This fact suggests the necessity of more information about the nature of why the students have poor pronunciation.

Question 9 discuses the students' problems in pronunciation before ET.

TABLE 8:

STUDENTS' PROBLEMS IN PRONUNCIATION BEFORE EXPERIMENTAL TEACHING

\begin{tabular}{|c|c|c|c|c|c|c|c|c|c|}
\hline & & $\begin{array}{c}\text { Final } \\
\text { sounds }\end{array}$ & $\begin{array}{c}\text { Extra } \\
\text { word-final } \\
\text { 's' }\end{array}$ & $\begin{array}{c}\text { Consonant } \\
\text { clusters }\end{array}$ & $\begin{array}{l}\text { Strange } \\
\text { sounds }\end{array}$ & $\begin{array}{l}\text { Long vowels } \\
\text { vs short } \\
\text { vowels }\end{array}$ & $\begin{array}{c}\text { Voiced } \\
\text { vs } \\
\text { voiceless }\end{array}$ & $\begin{array}{c}\text { Polysyllabic } \\
\text { words }\end{array}$ & $\begin{array}{l}\text { Connected } \\
\text { speech }\end{array}$ \\
\hline \multirow{2}{*}{ Valid } & Frequency & 45 & 17 & 39 & 40 & 48 & 35 & 30 & 54 \\
\hline & Percent & 83.3 & 31.5 & 72.2 & 74.1 & 88.9 & 64.8 & 55.6 & 100.0 \\
\hline
\end{tabular}

Problem $1=$ Omitting the word-final consonant

Problem $2=$ Adding the word-final $/ \mathrm{s} /$ to English words not ending in $/ \mathrm{s} /$

Problem $3=$ Adding the schwa $/ 6 /$ in the middle of a consonant cluster

Problem $4 \quad=$ Mispronouncing strange sounds to Vietnamese people, e.g. /T/ and /D/

Problem $5=$ Failing to differentiate between long and short vowels

Problem $6=$ Failing to differentiate between voiced and voiceless consonants 
Problem $7=$ Mispronouncing polysyllabic words

Problem $8=$ Mispronouncing connected speech

Problem $9=$ Mispronouncing word stress

As shown in Table 8, the first thing can be seen here is the high frequency of almost all the problems with an average of approximately $75 \%$ with the peak of Problem 2 at $100 \%$ and the trough of Problem 3 at $31.5 \%$. Most of these problems do not go beyond expectation, if not to say nearly the same as hypothesized. However, Problem 7, Problem 8 and Problem 9 are considered out of the scope of this research because these problems are more of further aspects of pronunciation than of discrete sounds, which is the research's focus. From now on, neither will these problems be further investigated nor does their statistics count the analyses of the whole data body in the research.

2. Results from Students' Questionnaire 2

Question 1 collects the students' opinion on the benefit of minimal pairs so as to validate the students' motivation for learning pronunciation with their support.

TABLE 9:
STUDENTS' OPINION ON THE BENEFITS OF MINIMAL PAIRS

\begin{tabular}{|c|c|c|c|c|c|}
\multicolumn{2}{c|}{} & \multicolumn{1}{c|}{ STUDENTS' OPINION ON THE BENEFITS OF MINIMAL PAIRS } \\
\cline { 2 - 6 } & Frequency & Percent & Valid Percent & Cumulative Percent \\
\hline \multirow{4}{*}{ Valid } & Very much & 36 & 66.7 & 66.7 & 66.7 \\
\cline { 2 - 6 } & Much & 14 & 25.9 & 25.9 & 92.6 \\
\cline { 2 - 6 } & Not much & 4 & 7.4 & 7.4 & 100.0 \\
\cline { 2 - 6 } & Total & 54 & 100.0 & 100.0 & 100.0 \\
\hline
\end{tabular}

As shown in Table 9, more than nine tenths of the students $(92.6 \%)$ are of the opinion that minimal pairs are of great benefit in pronunciation learning. Only a small number $(7.4 \%)$ think that such technique of acquiring discrete sounds brings little help. Thus, it can be inferred that minimal pairs increase the students' motivation for pronunciation learning.

Question 2 investigates how the students' awareness of pronunciation is raised after ET.

TABLE 10:

STUDENTS' RAISED AWARENESS OF PRONUNCIATION AFTER ET

\begin{tabular}{|c|c|c|c|c|c|}
\cline { 3 - 5 } \multicolumn{2}{c|}{} & Frequency & Percent & Valid Percent & Cumulative Percent \\
\hline \multirow{3}{*}{ Valid } & Very much & 40 & 74.1 & 74.1 & 74.1 \\
\cline { 2 - 6 } & Much & 14 & 25.9 & 25.9 & 100.0 \\
\cline { 2 - 6 } & Total & 54 & 100.0 & 100.0 & 100.0 \\
\hline
\end{tabular}

It is obvious that the students' awareness of pronunciation is raised more than expected (see Table 10). Maybe, it goes as a rule of nature: first comes their awareness; next comes their practice. Anyway, this is somewhat a success of the technique.

Question 3 finds out how often the students practise English pronunciation by themselves after experimental teaching.

TABLE 11:

STUDENTS' EXPECTED FREQUENCY OF PRONUNCIATION PRACTICE AFTER ET

\begin{tabular}{|c|c|c|c|c|c|}
\cline { 3 - 6 } \multicolumn{1}{c|}{} & Frequency & Percent & Valid Percent & Cumulative Percent \\
\hline \multirow{4}{*}{ Valid } & Very often & 30 & 55.6 & 55.6 & 55.6 \\
\cline { 2 - 6 } & Often & 20 & 37.0 & 37.0 & 92.6 \\
\cline { 2 - 6 } & Sometimes & 4 & 7.4 & 7.4 & 100.0 \\
\cline { 2 - 6 } & Total & 54 & 100.0 & 100.0 & 100.0 \\
\hline
\end{tabular}

Most of the students $(92.6 \%)$ tend to practise pronunciation often or very often after experimental teaching (see Table 11). This fact indicates that the technique has built up a fresh impetus for pronunciation learning among the students.

Question 4 aims at students' interest level in learning pronunciation with minimal pairs so as to evaluate their motivation for this technique.

TABLE 12:

STUDENTS’ INTEREST IN LEARNING PRONUNCIATION WITH MINIMAL PAIRS

\begin{tabular}{|c|c|c|c|c|c|}
\multicolumn{2}{c|}{} & STUDENTS' INTEREST IN LEARNING PRONUNCIATION WITH MINIMAL PAIRS \\
\cline { 2 - 6 } \multicolumn{1}{c|}{} & Frequency & Percent & Valid Percent & Cumulative Percent \\
\hline \multirow{3}{*}{ Valid } & Very interesting & 35 & 64.8 & 64.8 & 64.8 \\
\cline { 2 - 6 } & Interesting & 15 & 27.8 & 27.8 & 92.6 \\
\cline { 2 - 6 } & Not very interesting & 4 & 7.4 & 7.4 & 100.0 \\
\cline { 2 - 6 } & Total & 54 & 100.0 & 100.0 & 100.0 \\
\hline
\end{tabular}

Almost all the students (92.6\%) find it interesting to learn English discrete sounds with minimal pairs (see Table 12). This fact both indicates that the technique employed is highly applicable at least to the student subjects and confirms its essentiality in pronunciation teaching. 
Question 5 helps identify which activities are most attractive to the students based on their own interest level in the activities carried out.

TABLE 13:

STUDENTS' OPINION ON THE CLASSROOM ACTIVITIES

\begin{tabular}{|c|c|c|c|c|c|}
\cline { 2 - 5 } \multicolumn{2}{c|}{} & Frequency & Percent & Valid Percent & Cumulative Percent \\
\hline \multirow{4}{*}{ Valid } & Presentation & 9 & 16.7 & 16.7 & 16.7 \\
\cline { 2 - 6 } & Practice & 10 & 18.5 & 18.5 & 35.2 \\
\cline { 2 - 6 } & Exercises and games & 35 & 64.8 & 64.8 & 100.0 \\
\cline { 2 - 6 } & Total & 54 & 100.0 & 100.0 & 100.0 \\
\hline
\end{tabular}

As displayed in Table 13, more or less, all activities conducted during ET could draw the students' attention. Of these activities, games are the most interesting. However, the presentation and controlled practice have their own functions which are considered to be decisive factors in pronunciation teaching.

Question 6 investigates students' expectation of frequency of pronunciation class after experimental teaching.

TABLE 14:

STUDENTS' EXPECTED FREQUENCY OF PRONUNCIATION CLASSES

\begin{tabular}{|c|c|c|c|c|c|}
\hline & & Frequency & Percent & Valid Percent & Cumulative Percent \\
\hline \multirow{4}{*}{ Valid } & Very often & 40 & 74.1 & 74.1 & 74.1 \\
\hline & Often & 10 & 18.5 & 18.5 & 92.6 \\
\hline & Sometimes & 4 & 7.4 & 7.4 & 100.0 \\
\hline & Total & 54 & 100.0 & 100.0 & 100.0 \\
\hline
\end{tabular}

Most of the students $(89.6 \%)$ expect more exposure to pronunciation learning in class (see Table 14). This fact suggests that the students have made their way to pronunciation learning. With the provision of this access, they wish to go further into other aspects of pronunciation.

Question 7 identifies which English sounds are most problematic for the students to acquire. Such identification is supposed to validate the suggested solutions to the students' problems in English pronunciation.

TABLE 15:

TABLE 15:
STUDENTS' CHOICE OF THE MOST DIFFICULT SOUNDS TO LEARN

\begin{tabular}{|c|c|c|c|c|c|}
\cline { 3 - 5 } \multicolumn{2}{c|}{} & Frequency & Percent & Valid Percent & Cumulative Percent \\
\hline \multirow{5}{*}{ Valid } & Vowels & 20 & 37.0 & 37.0 & 37.0 \\
\cline { 2 - 6 } & Consonants & 20 & 37.0 & 37.0 & 74.1 \\
\cline { 2 - 6 } & Diphthongs & 10 & 18.5 & 18.5 & 92.6 \\
\cline { 2 - 6 } & All three & 4 & 7.4 & 7.4 & 100.0 \\
\cline { 2 - 6 } & Total & 54 & 100.0 & 100.0 & 100.0 \\
\hline
\end{tabular}

Nearly three quarters $(74 \%)$ of the students find that both English vowels and consonants are more difficult to learn than diphthongs (see Table 15). This asserts that the focus on discrete sounds of this research practically fits well with the students' need.

Question 8 collects the students' after EP suggestions of how to solve their own problems. These suggestions partially serve as the basis on which further suggestions for the teaching and learning in such setting are launched.

TABLE 16:

STUDENTS' AFTER ET SUGGESTIONS OF HOW TO SOLVE THEIR OWN PROBLEMS

\begin{tabular}{|c|c|c|c|c|c|}
\cline { 3 - 6 } & \multicolumn{2}{c|}{ Frequency } & Percent & Valid Percent & Cumulative Percent \\
\hline \multirow{4}{*}{ Valid } & Vowels & 20 & 37.0 & 37.0 & 37.0 \\
\cline { 2 - 6 } & Consonants & 20 & 37.0 & 37.0 & 74.1 \\
\cline { 2 - 6 } & Diphthongs & 10 & 18.5 & 18.5 & 92.6 \\
\cline { 2 - 6 } & All three & 4 & 7.4 & 7.4 & 100.0 \\
\cline { 2 - 6 } & Total & 54 & 100.0 & 100.0 & 100.0 \\
\hline
\end{tabular}




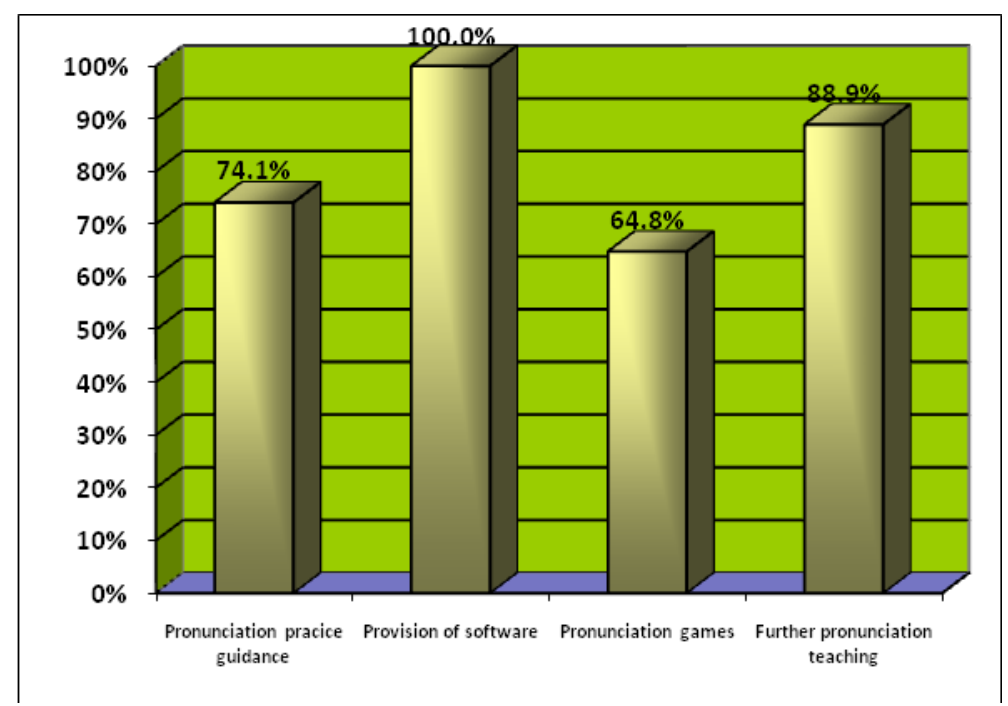

Figure 13: Students' after ET suggestions of how to solve their own problems

Since they are of a wide range, the students' suggestions are divided into four groups according to their closeness in the nature of what is suggested (as in Figure 13) for the sake of subsequent analyses. The statistics show that all the four groups of suggestions are of great importance because they come from the majority of the students. In the first place are the softwares used during ET; in other words, audiovisual demonstration of the production of discrete sounds is of great assistance. The suggestions of further pronunciation teaching once again confirms the students' determination to go deeper into English pronunciation as inferred from their responses to Question 6. The suggestions of pronunciation practice guidance indicate the students' persistence in self-improving their pronunciation.

3. Results from Teachers' Questionnaire

Question 1 collects the teachers' opinion on the benefit of minimal pairs in pronunciation teaching.

TABLE 17:

TEACHERS' OPINION ON THE BENEFITS OF MINIMAL PAIRS IN PRONUNCIATION TEACHING

\begin{tabular}{|c|c|c|c|c|c|}
\cline { 3 - 6 } \multicolumn{2}{c|}{} & Frequency & Percent & Valid Percent & Cumulative Percent \\
\hline \multirow{4}{*}{ Valid } & Very much & 15 & 75.0 & 75.0 & 75.0 \\
\cline { 2 - 6 } & Much & 3 & 15.0 & 15.0 & 90.0 \\
\cline { 2 - 6 } & Not much & 2 & 10.0 & 10.0 & 100.0 \\
\cline { 2 - 6 } & Total & 20 & 100.0 & 100.0 & 100.0 \\
\hline
\end{tabular}

Almost all the teachers (90\%) appreciate the great benefits of minimal pairs in pronunciation teaching (see Table 17). Once again, this appreciation consolidates the effectiveness of minimal pairs as a means to teach English discrete sounds to EFL learners.

Question 2 collects the teachers' evaluation of their students' motivation for learning English discrete sounds with minimal pairs so as to add reliability to the study's conclusion of the responding issue.

TABLE 18:

\begin{tabular}{|c|c|c|c|c|c|}
\hline & & Frequency & Percent & Valid Percent & Cumulative Percent \\
\hline \multirow{3}{*}{ Valid } & Very much & 16 & 80.0 & 80.0 & 80.0 \\
\hline & Much & 4 & 20.0 & 20.0 & 100.0 \\
\hline & Total & 20 & 100.0 & 100.0 & 100.0 \\
\hline
\end{tabular}

As shown in Table 18, most of the teachers' observations indicate that their students are highly motivated to learn English discrete sounds with the teaching technique employed. Together with the findings from the analysis of the student subjects' responses to Question 4 in Students' Questionnaire 2, this fact confirms the student population's high motivation for learning English discrete sounds with minimal pairs.

Question 3 focuses on the teachers' expected frequency of pronunciation teaching in their own classes. 
TABLE 19:

TEACHERS' EXPECTED FREQUENCY OF PRONUNCIATION TEACHING

\begin{tabular}{|c|c|c|c|c|c|}
\cline { 3 - 6 } \multicolumn{2}{c|}{} & Frequency & Percent & Valid Percent & Cumulative Percent \\
\hline \multirow{3}{*}{ Valid } & Very often & 17 & 85.0 & 85.0 & 85.0 \\
\cline { 2 - 6 } & Often & 3 & 15.0 & 15.0 & 100.0 \\
\cline { 2 - 6 } & Total & 20 & 100.0 & 100.0 & 100.0 \\
\hline
\end{tabular}

Table 19 shows that most of the teachers $(85 \%)$ wish to teach pronunciation very often. This fact suggests that their students' problems would be similar to those facing the student subjects and that it be necessary to give Hung Vuong university students in general and the student subjects in particular more chances to learn and practise English pronunciation so as to improve the situation.

Question 4 aims to find out how much time the teachers spend on designing classroom activities with minimal pairs.

TABLE 20:

TIME SPENT ON DESIGNING CLASSROOM ACTIVITIES WITH MINIMAL PAIRS

\begin{tabular}{|c|c|c|c|c|c|}
\cline { 2 - 6 } \multicolumn{2}{c|}{} & Frequency & Percent & Valid Percent & Cumulative Percent \\
\hline \multirow{4}{*}{ Valid } & $\mathbf{1 ~ - ~ 2 ~ h o u r s ~}$ & 10 & 50.0 & 50.0 & 50.0 \\
\cline { 2 - 6 } & $\mathbf{3}-\mathbf{4}$ hours & 8 & 40.0 & 40.0 & 90.0 \\
\cline { 2 - 6 } & Days & 2 & 10.0 & 10.0 & 100.0 \\
\cline { 2 - 6 } & Total & 20 & 100.0 & 100.0 & 100.0 \\
\hline
\end{tabular}

Most of the teachers agree that it takes about 3 hours or so to design minimal pairs into classroom activities for teaching discrete sounds (see Table 20). That is not a long time. That means such activities can be available within a few hours and some effort.

Question 5 seeks for the teachers' choice of suitable activities in which minimal pairs can be employed as a means in teaching pronunciation.

TABLE 21:

TEACHERS' CHOICE OF SUITABLE ACTIVITIES EMPLOYING MINIMAL PAIRS

\begin{tabular}{|c|c|c|c|c|c|c|c|c|}
\cline { 3 - 9 } \multicolumn{2}{c|}{} & Recognition & Matching & $\begin{array}{c}\text { Tongue } \\
\text { twisters }\end{array}$ & $\begin{array}{c}\text { Bingo } \\
\text { sheets }\end{array}$ & Flash cards & Conversations & Others \\
\hline \multirow{2}{*}{ Valid } & Frequency & 20 & 20 & 19 & 18 & 18 & 17 \\
\cline { 2 - 10 } & Percent & 100.0 & 100.0 & 95.0 & 90.0 & 90.0 & 85.0 & 15.0 \\
\hline
\end{tabular}

As shown in Table 21, the teachers' opinions show that almost all the activities employed in ET are of great suitability to the student subjects. Some more activities are also recommended by the teachers, leading to the conclusion that in general the activities suggested by the study are practically applicable to the technique employed in the research.

Question 6 aims at the teachers' opinion on which sounds they think are the most difficult to teach to their students.

TABLE 22:

\begin{tabular}{|c|c|c|c|c|c|}
\hline & & Frequency & Percent & Valid Percent & Cumulative Percent \\
\hline \multirow{3}{*}{ Valid } & Vowels & 10 & 50.0 & 50.0 & 50.0 \\
\hline & Consonants & 10 & 50.0 & 50.0 & 100.0 \\
\hline & Total & 20 & 100.0 & 100.0 & 100.0 \\
\hline
\end{tabular}

All of the teachers accept that English discrete sounds are more difficult to teach to the students (see Table 22). This fact states the same viewpoint as reflected in the students' responses to Question 7 in Students' Questionnaire 2. Such coincidence is believed to validate the significance hypothesized in the research.

Question 7 focuses on the teachers' opinions on which teaching aids are useful for pronunciation teaching.

TABLE 23:

TEACHERS' OPINION ON TEACHING AIDS FOR PRONUNCIATION TEACHING

\begin{tabular}{|c|c|c|c|c|c|c|c|}
\cline { 3 - 8 } \multicolumn{2}{c|}{} & CD-layer & Flash cards & $\begin{array}{c}\text { LCD } \\
\text { projector }\end{array}$ & OHP & Pictures & Realia \\
\hline \multirow{2}{*}{ Valid } & Frequency & 20 & 19 & 19 & 6 & 18 & 14 \\
\cline { 2 - 8 } & Percent & 100.0 & 95.5 & 100.0 & 30.0 & 90.0 \\
\hline
\end{tabular}


Teachers' opinions on teaching aids prove that audiovisual aids are so important in pronunciation teaching: in the first place are the LCD projector and CD player; of the second choice are flash cards and pictures; next comes realia. These items are of very high rate of choice, all being over $90 \%$ (see Table 23 ).

Question 8 finds out from what sources the teachers often get minimal pairs for their pronunciation teaching.

TABLE 24:

TEACHERS' SOURCES OF MINIMAL PAIRS FOR THEIR PRONUNCIATION TEACHING

\begin{tabular}{|c|c|c|c|c|}
\cline { 3 - 5 } \multicolumn{1}{c|}{} & Frequency & Percent & Valid Percent \\
\hline \multirow{4}{*}{ Valid } & Books & 20 & 100.0 & 100.0 \\
\cline { 2 - 5 } & Internet & 20 & 100.0 & 100.0 \\
\cline { 2 - 5 } & Experience & 14 & 70.0 & 70.0 \\
\cline { 2 - 5 } & Friends & 12 & 60.0 & 60.0 \\
\hline
\end{tabular}

As displayed in Table 24, all of the teachers state that the Internet and textbooks are the most common sources where minimal pairs are available. Sources of these kinds are within reach of both teachers and students. Such availability fosters the applicability of the teaching technique and saves teachers a great deal of time. It is also the Internet that facilitates the sharing of such sources among teachers who are in need of minimal pairs. This convenience makes it even more possible to employ minimal-pair exercises and games even online if Internet access is available in the classroom.

Question 9 focuses on the teachers' evaluation of the students' pronunciation improvement. The data collected from the teachers' responses to this question is one of the factors which indicate the effectiveness of the study's suggested teaching technique.

TABLE 25:

TEACHERS' EVALUATION OF THEIR STUDENTS' PRONUNCIATION IMPROVEMENT

\begin{tabular}{|c|c|c|c|c|c|}
\cline { 2 - 6 } \multicolumn{2}{c|}{} & Frequency & Percent & Valid Percent & Cumulative Percent \\
\hline \multirow{4}{*}{ Valid } & Very much & 12 & 60.0 & 60.0 & 60.0 \\
\cline { 2 - 6 } & Much & 5 & 25.0 & 25.0 & 85.0 \\
\cline { 2 - 6 } & Not much & 3 & 15.0 & 15.0 & 100.0 \\
\cline { 2 - 6 } & Total & 20 & 100.0 & 100.0 & 100.0 \\
\hline
\end{tabular}

Table 24 shows that the majority of the teachers (85\%) assert the considerable improvement of their students' pronunciation. None of the teachers negate the progress that their students made. This confirms the effectiveness of the teaching technique employed in the research.

Question 10 collects data of the teachers' opinion on how accurate their assessment of their students' pronunciation improvement is.

TABLE 26:

TEACHERS' OPINION ON HOW ACCURATE THEIR ASSESSMENT OF THEIR STUDENTS' PRONUNCIATION IMPROVEMENT IS

\begin{tabular}{|c|c|c|c|c|c|}
\cline { 2 - 6 } \multicolumn{2}{c|}{} & Frequency & Percent & Valid Percent & Cumulative Percent \\
\hline \multirow{4}{*}{ Valid } & Very accurate & 6 & 30.0 & 30.0 & 30.0 \\
\cline { 2 - 6 } & Accurate & 12 & 60.0 & 60.0 & 90.0 \\
\cline { 2 - 6 } & Not very accurate & 2 & 10.0 & 10.0 & 100.0 \\
\cline { 2 - 6 } & Total & 20 & 100.0 & 100.0 & 100.0 \\
\hline
\end{tabular}

Almost all the teachers (90\%) believe that their assessment is reliable. Only a small proportion (10\%) is not quite sure of this reliability (see Table 26). None of the teachers deny the accuracy of their assessment. This allows statistics of such evaluation to be considered as sufficiently dependable.

Question 11 focuses on what problems the teachers encounter in teaching pronunciation. The difficulties reported in Teachers' Questionnaire can be grouped as follows:

Difficulty 1

Difficulty 2

Difficulty 3

Difficulty 4

Difficulty 5
$=$ Lack of audiovisual aids

$=$ Interference of students' L1 acquisition

$=$ Students' poor awareness of pronunciation accuracy

$=$ Students' low motivation for pronunciation learning

$=$ Others 
Difficulties included in the first four groups are similar to what was hypothesized. Thus, the application of the teaching aids employed in the research turns out to be of great suitability; and the recommendations of this research seem to be feasible solutions to these problems.

Question 12 builds up a collection of the teachers' suggestions for teaching pronunciation to the whole population at Hung Vuong University.

The suggestions focus on (1) more equipment for the teaching and learning process, recommended by $90 \%$ of the teachers; (2) reformation of the way students are tested, i.e. more weight should be counted on pronunciation, suggested by the same percentage; (3) more time for pronunciation teaching in class, advocated by $80 \%$; and (4) application of new and suitable teaching techniques, endorsed by three quarters. The other pieces of advice such as inviting native teachers or holding one or more English speaking clubs seem to be also practically useful. However, the two last are quite far from the focus of the research, being excluded from the analysis of this section.

As far as concerned, the above-mentioned four main groups of suggestions reconsolidate the rationale as well as the significance of the research.

\section{B. Results from the Recordings and Test Scores}

As reflected in their responses Students' Questionnaire 1, it is obvious that the student subjects face pronunciation problems which directly originate from their poor production and recognition of English discrete sounds. This conclusion is further supported by the analysis of the data from Teachers' Questionnaire, Diagnostic Test, Pre-experiment Recordings together with the outcomes of the interviews and observations carried out. In addition, the student subjects from different geographical regions suffer from different English sounds.

For further evidence, also mentioned hereafter are some spectrograms of the students' production before ET.

Within the scope of this research, the researcher would like to present only one typical case for each type of the mistakes $^{12}$ in question.

For Mistake 1 (Omitting the word-final consonant) (see Figure 14)

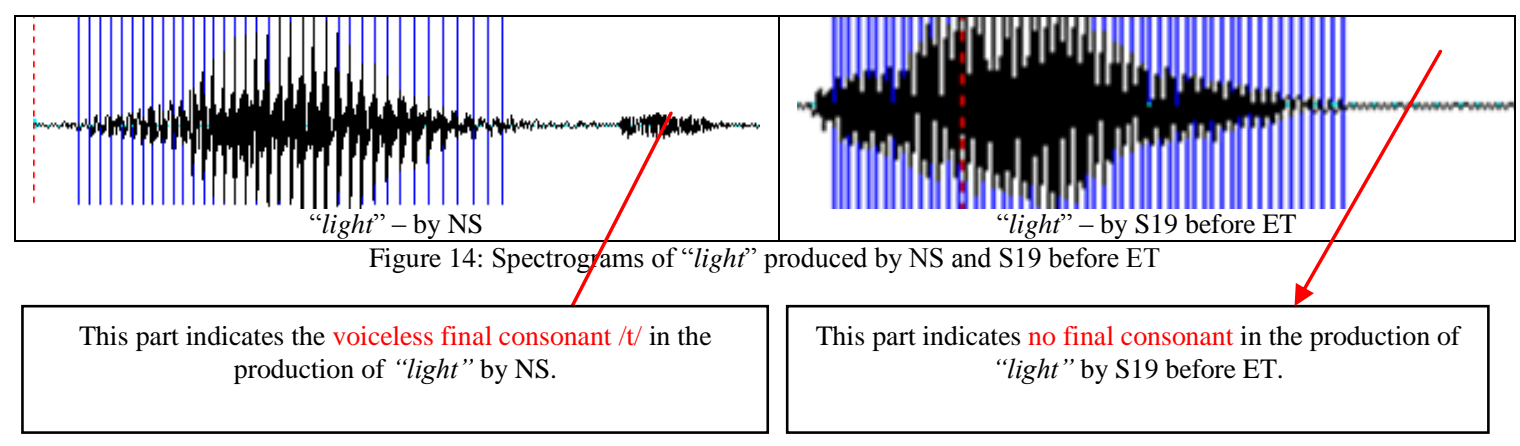

For Mistake 2 (Adding the word-final /s/ to English words not ending in /s/) (see Figure 15)

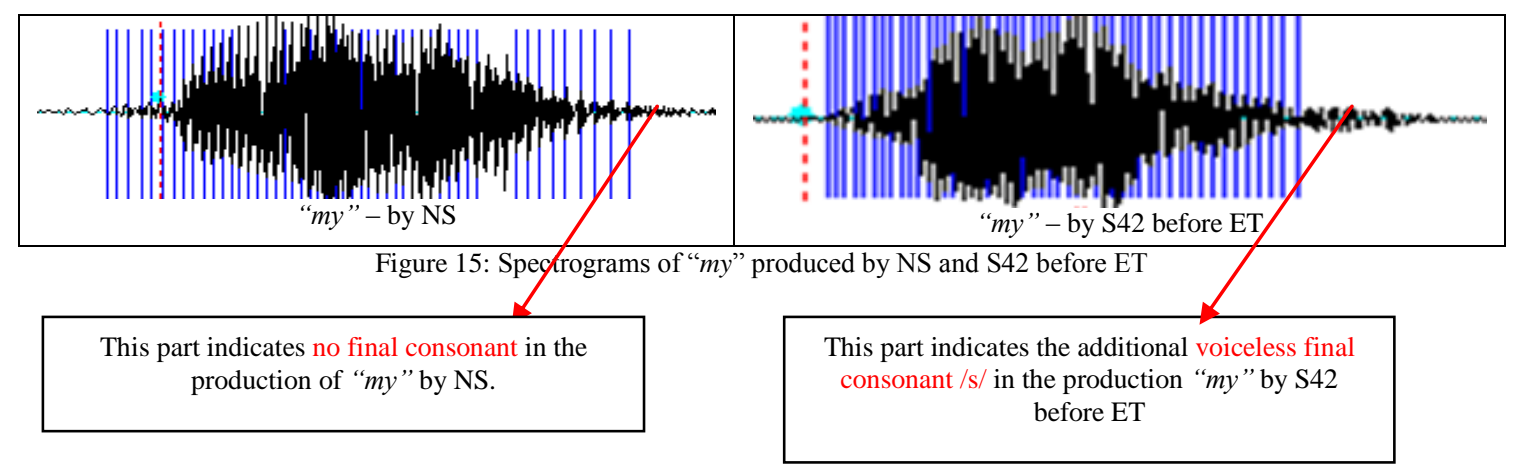

${ }^{12}$ A mistake "is caused by lack of attention, fatigue, carelessness, or some other aspects of performance." (Richards et al., 1993: 127) 
For Mistake 3 (Adding the schwa /6/ in the middle of a consonant cluster) (see Figure 16)

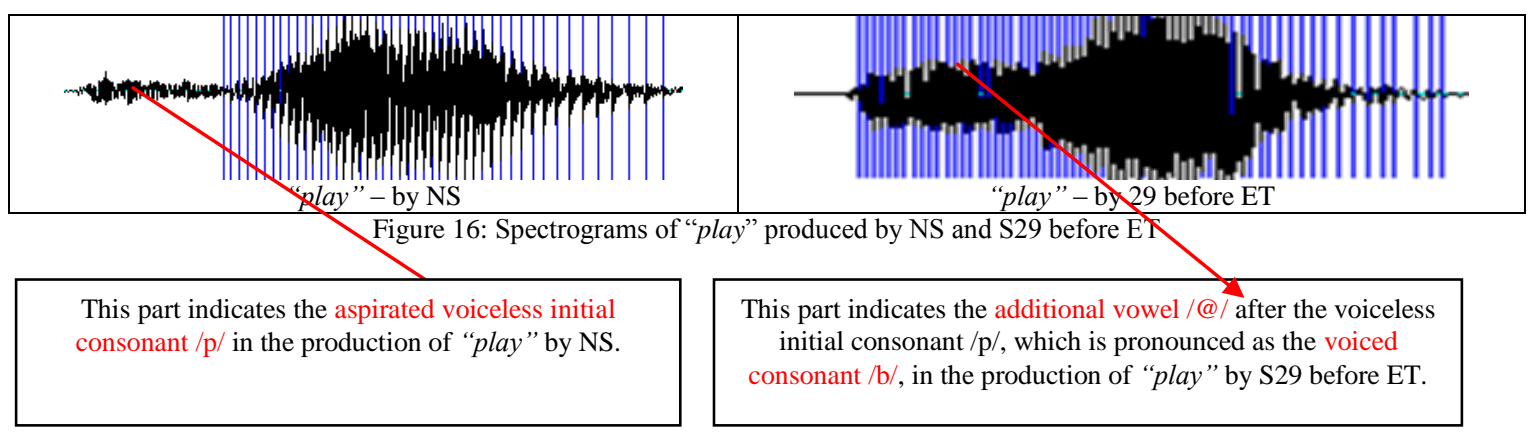

For Mistake 4 (Mispronouncing strange sounds to Vietnamese people, e.g. /T/ and /D/) (see Figure 17)

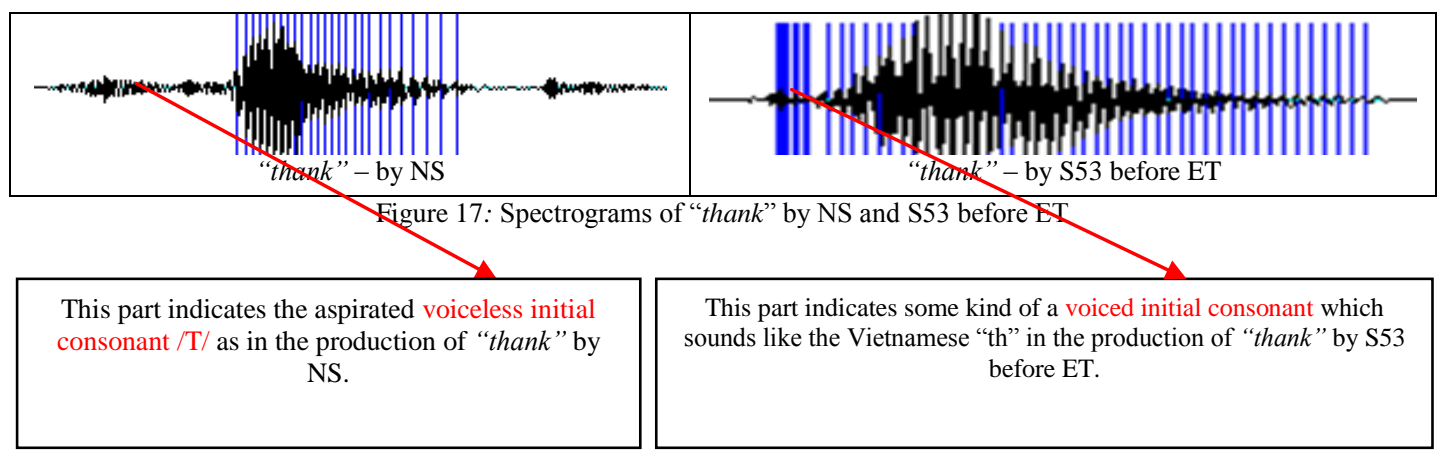

For Mistake 5 (Failing to differentiate between long and short vowels) (see Figure 18)

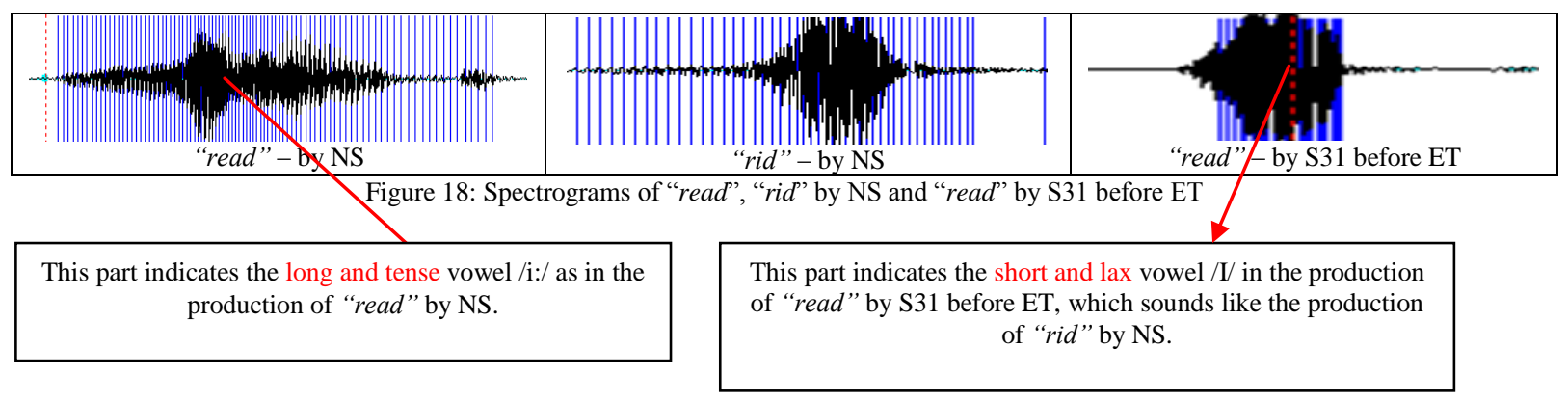

For Mistake 6 (Failing to differentiate between voiced and voiceless consonants) (see Figure 19)

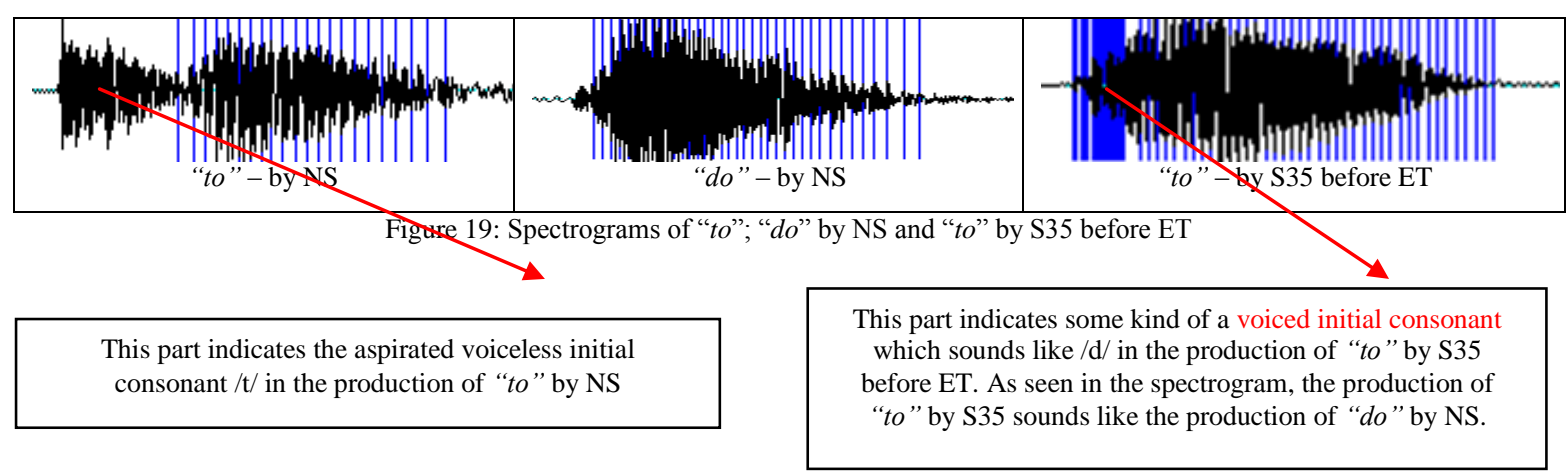

The above analyses show that the student subjects' poor acquisition of English discrete sounds that result in their problems of English pronunciation.

The following demonstrates the benefits of minimal pairs as a tool (1) to raise the students' awareness of pronunciation, (2) to improve both their recognition and production of English discrete sounds, and (3) to point out the path for these students to get closer to further aspects of English pronunciation. 
TABLE 27:

OVERALL CALCULATION OF STUDENTS' SCORES IN THE TWO TESTS

\begin{tabular}{|c|c|c|c|c|c|c|}
\hline \multirow{2}{*}{ GROUP } & \multicolumn{2}{|c|}{ DIAGNOSTIC TEST } & \multicolumn{2}{c|}{ ACHIEVEMENT TEST } & \multicolumn{2}{c|}{ STUDENTS' PROGRESS } \\
\cline { 2 - 7 } & Frequency & Percent & Frequency & Percent & Frequency & Percent \\
\hline G1 & $\mathbf{1 0}$ & $\mathbf{1 8 . 5 \%}$ & $\mathbf{0 2}$ & $\mathbf{0 3 . 7 \%}$ & $\mathbf{0 8}$ & $\mathbf{1 4 . 8 \%}$ \\
\hline G2 & $\mathbf{4 0}$ & $\mathbf{7 1 . 1 \%}$ & $\mathbf{1 8}$ & $\mathbf{3 3 . 3 \%}$ & $\mathbf{2 2}$ & $\mathbf{4 0 . 7 \%}$ \\
\hline G3 & $\mathbf{0 4}$ & $\mathbf{7 . 4 \%}$ & $\mathbf{3 0}$ & $\mathbf{5 5 . 6 \%}$ & $\mathbf{2 6}$ & $\mathbf{4 8 . 1 \%}$ \\
\hline G4 & $\mathbf{0 0}$ & $\mathbf{0 . 0 \%}$ & $\mathbf{0 4}$ & $\mathbf{0 7 . 4 \%}$ & $\mathbf{0 4}$ & $\mathbf{0 7 . 4 \%}$ \\
\hline
\end{tabular}

Table 27 shows that all of the four groups made considerable progress after ET, especially the sharp increase in number of G2 (the group of average students) and G3 (the group of good students). More importantly, the appearance of G4 (the group of excellent students) serves as an assertion of the "depth" of the students' progress.

TABLE 28:

OVERALL CALCULATION OF STUDENTS’ MISTAKES IN THE TWO SETS OF RECORDINGS

\begin{tabular}{|c|c|c|c|c|c|c|}
\hline \multirow{2}{*}{ MISTAKE } & \multicolumn{2}{|c|}{ PRE-EXPERIMENT RECORDINGS } & \multicolumn{2}{|c|}{ POST-EXPERIMENT RECORDINGS } & \multicolumn{2}{|c|}{ STUDENTS' PROGRESS } \\
\hline & Frequency & Percent & Frequency & Percent & Frequency & Percent \\
\hline M1 & 42 & $77.7 \%$ & 15 & $27.7 \%$ & 27 & $50.0 \%$ \\
\hline M2 & 20 & $37.0 \%$ & 06 & $11.1 \%$ & 14 & $25.9 \%$ \\
\hline M3 & 29 & $53.7 \%$ & 14 & $25.9 \%$ & 15 & $27.8 \%$ \\
\hline M4 & 48 & $88.8 \%$ & 20 & $37.0 \%$ & 28 & $51.80 \%$ \\
\hline M5 & 39 & $72.2 \%$ & 21 & $38.8 \%$ & 18 & $33.4 \%$ \\
\hline M6 & 33 & $61.1 \%$ & 10 & $18.5 \%$ & 23 & $42.6 \%$ \\
\hline
\end{tabular}

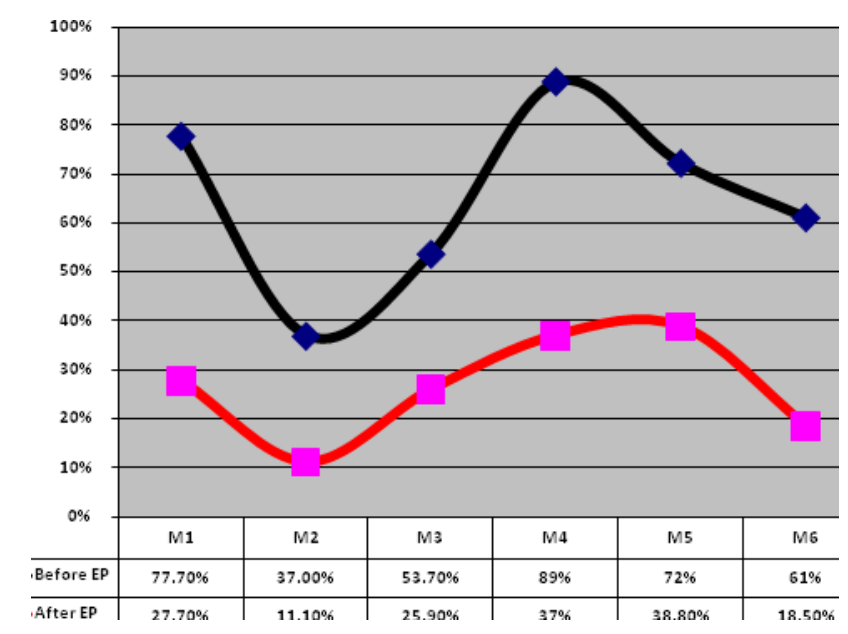

Figure 20: Distribution of mistake groups before and after ET

As inferred from Table 28 and Figure 20, the frequency of all mistake groups made by the students decreases remarkably after ET. Together with the above-mentioned analysis from the results of the two tests, it is obvious that the students made great progress both in recognition and production at word level.

TABLE 29:

FREQUENCY OF STUDENTS' SELF-STUDYING ENGLISH PRONUNCIATION BEFORE AND AFTER ET

\begin{tabular}{|c|c|c|c|c|c|c|}
\hline \multirow{2}{*}{ FREQUENCY } & \multicolumn{2}{|c|}{ BEFORE ET } & \multicolumn{2}{|c|}{ AFTER ET } & \multicolumn{2}{|c|}{ GROWTH } \\
\hline & Frequency & Percent & Frequency & Percent & Frequency & Percent \\
\hline Very often & 0 & $\mathbf{0}$ & 30 & 55.6 & 30 & 55.6 \\
\hline Often & 6 & 11.1 & 20 & 37 & 14 & 25.9 \\
\hline Sometimes & 36 & 66.7 & 4 & 7.4 & 32 & 59.2 \\
\hline Never & 12 & 22.2 & $\mathbf{0}$ & 0 & 12 & 22.2 \\
\hline
\end{tabular}




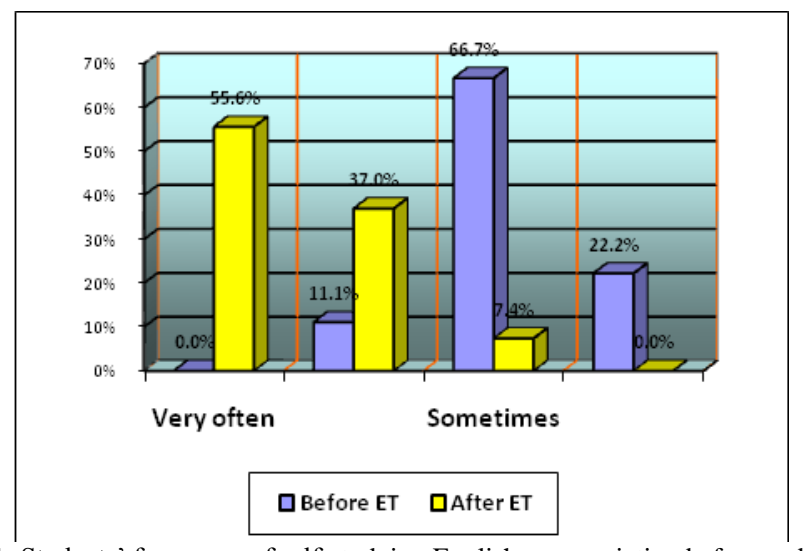

Figure 21: Students' frequency of self-studying English pronunciation before and after ET

As seen in Table 29 and Figure 21, the students' self-studying pronunciation rockets after ET. This partially indicates that the students have made their own ways to further aspects of pronunciation after attending the experimental pronunciation classes.

Together with these findings, the practical effectiveness and pedagogical benefits of minimal pairs employed in pronunciation teaching can be supported by the statistics from the students' responses to Question 1 and Question 4 of Students' Questionnaire 2 and from the teachers' responses to Question 1 and Question 2 of Teachers' Questionnaire.

As far as concerned, it seems advisable to consider some more spectrograms of the students' production before and after ET. By comparing the students' production at these times with that of the native speaker, the students' progress will be more reliably investigated. Hereafter are mentioned the analyses of the same cases as previously presented, one case for one mistake group.

For Mistake 1 (Omitting the word-final consonant) (see Figure 22)

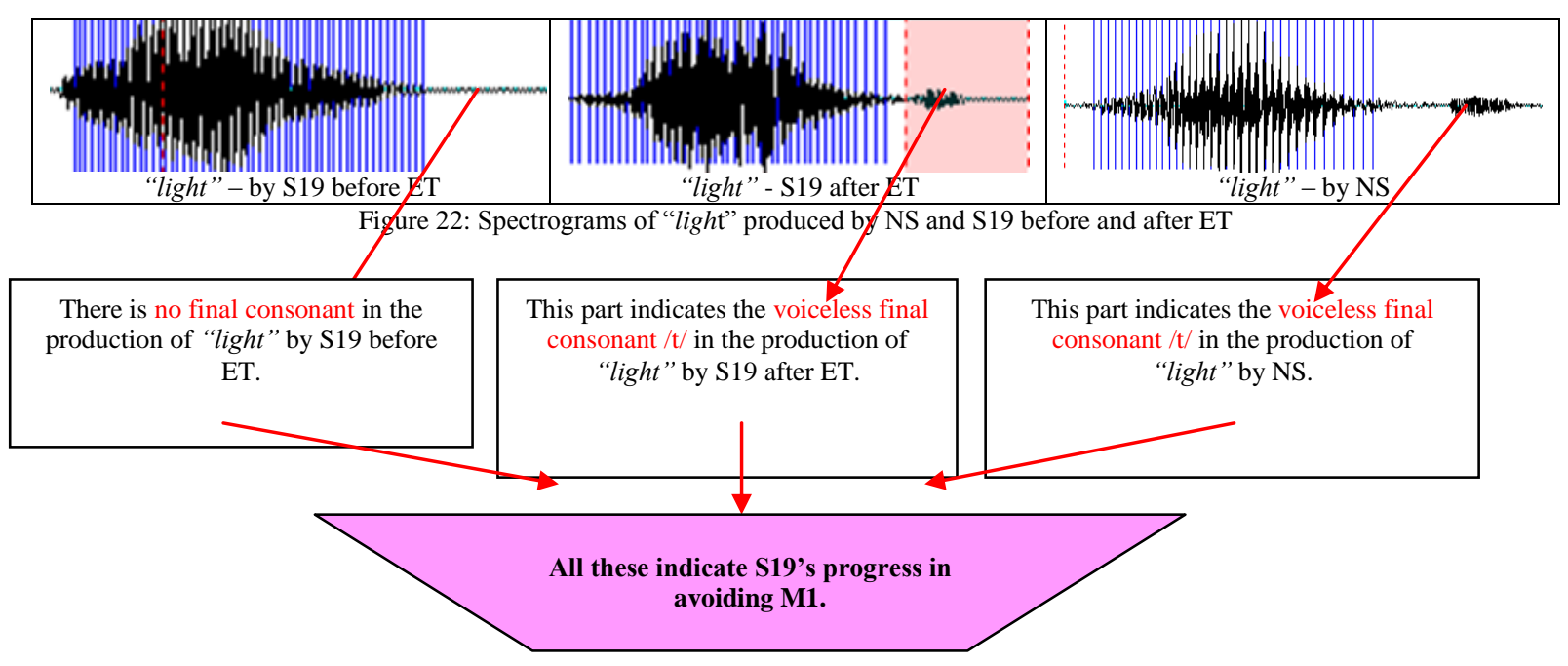

For Mistake 2 (Adding the word-final /s/ to English words not ending in /s/) (see Figure 23)

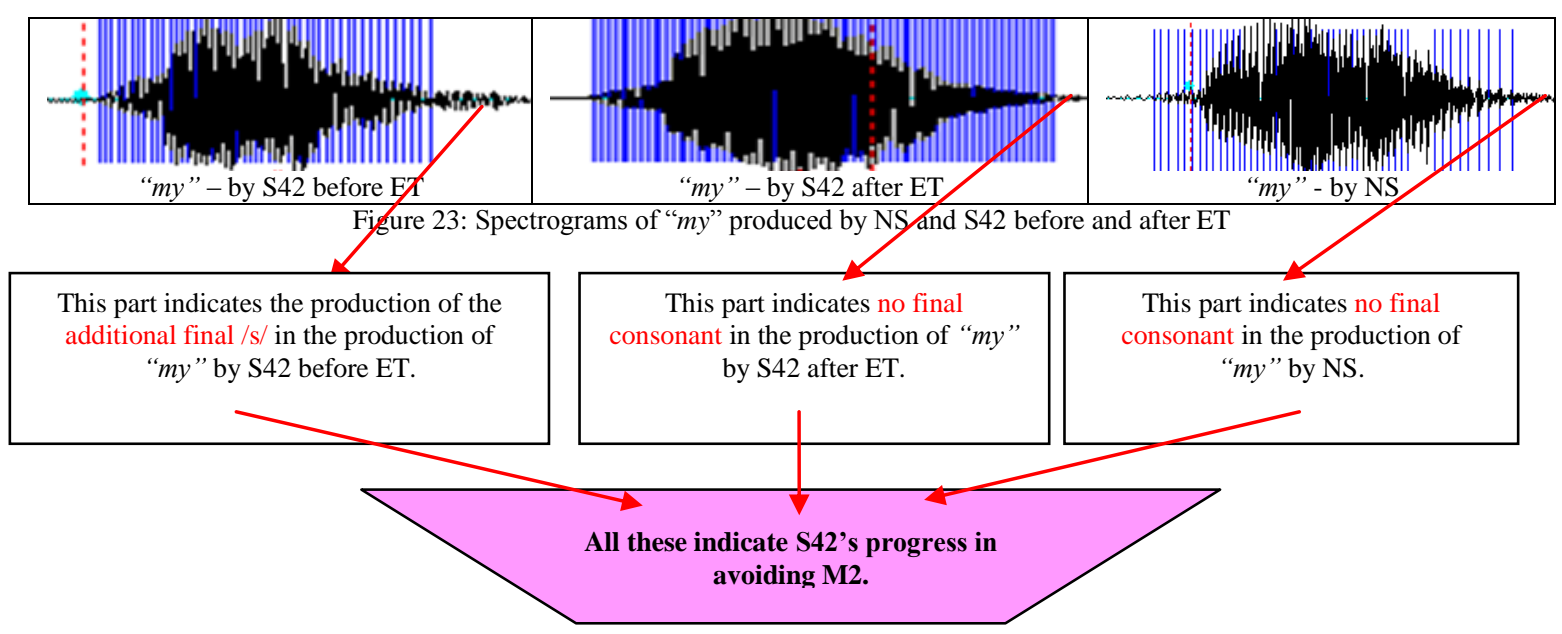


For Mistake 3 (Adding the schwa /6/ in the middle of a consonant cluster) (see Figure 24)

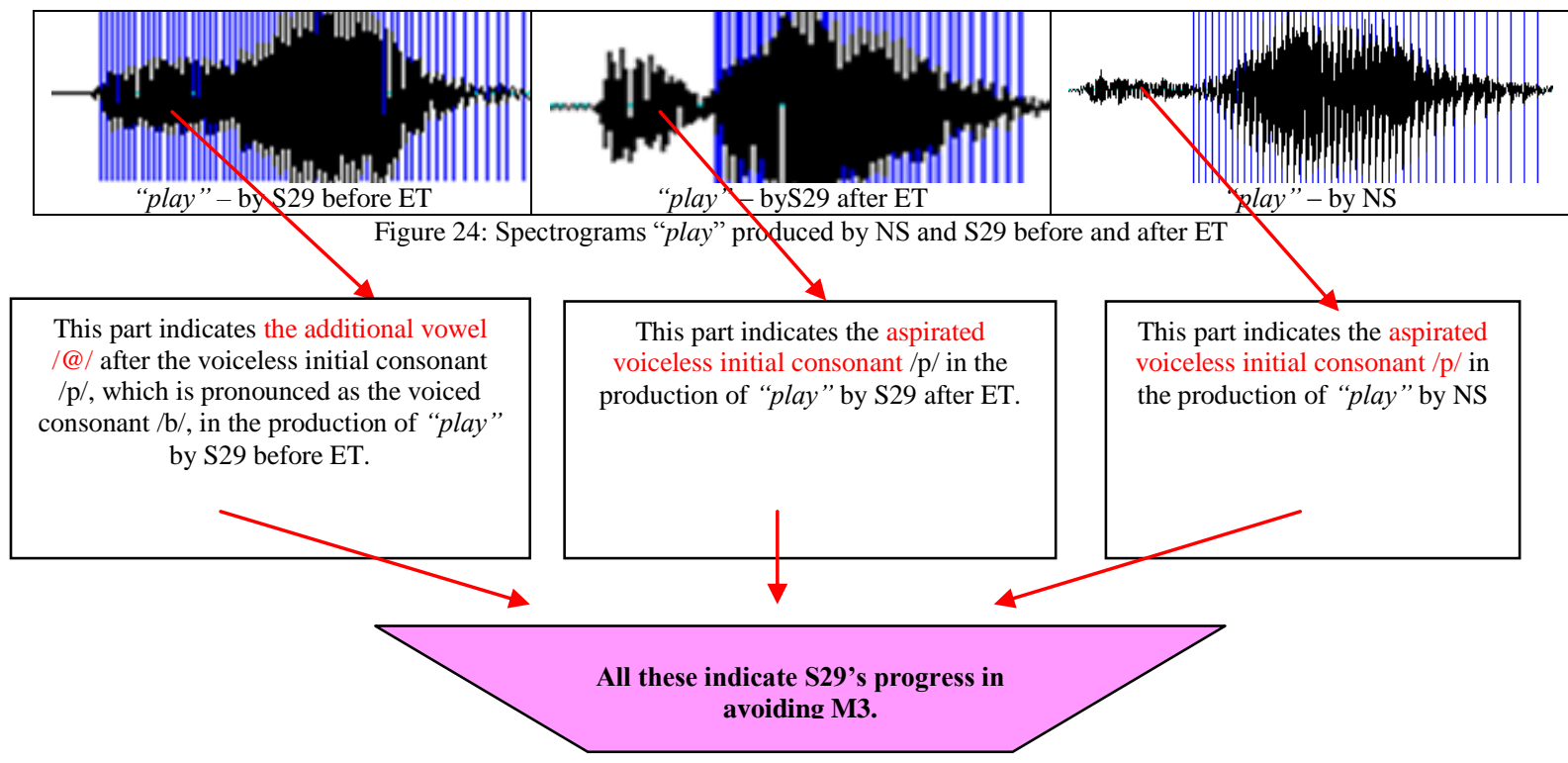

For Mistake 4 (Mispronouncing strange sounds to Vietnamese people, e.g. /T/ and /D/) (see Figure 25)

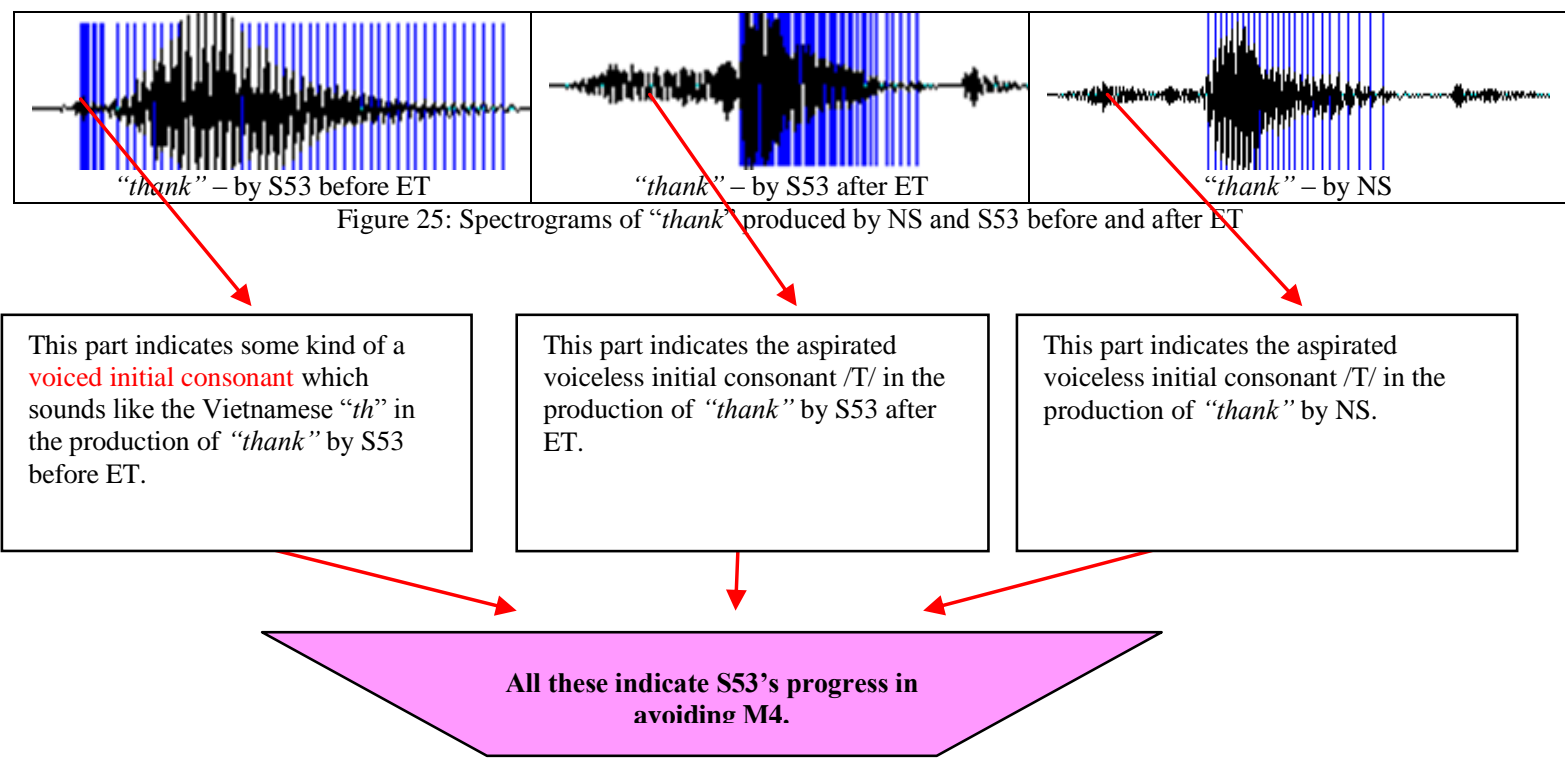

For Mistake 5 (Failing to differentiate between long and short vowels) (see Figure 26)

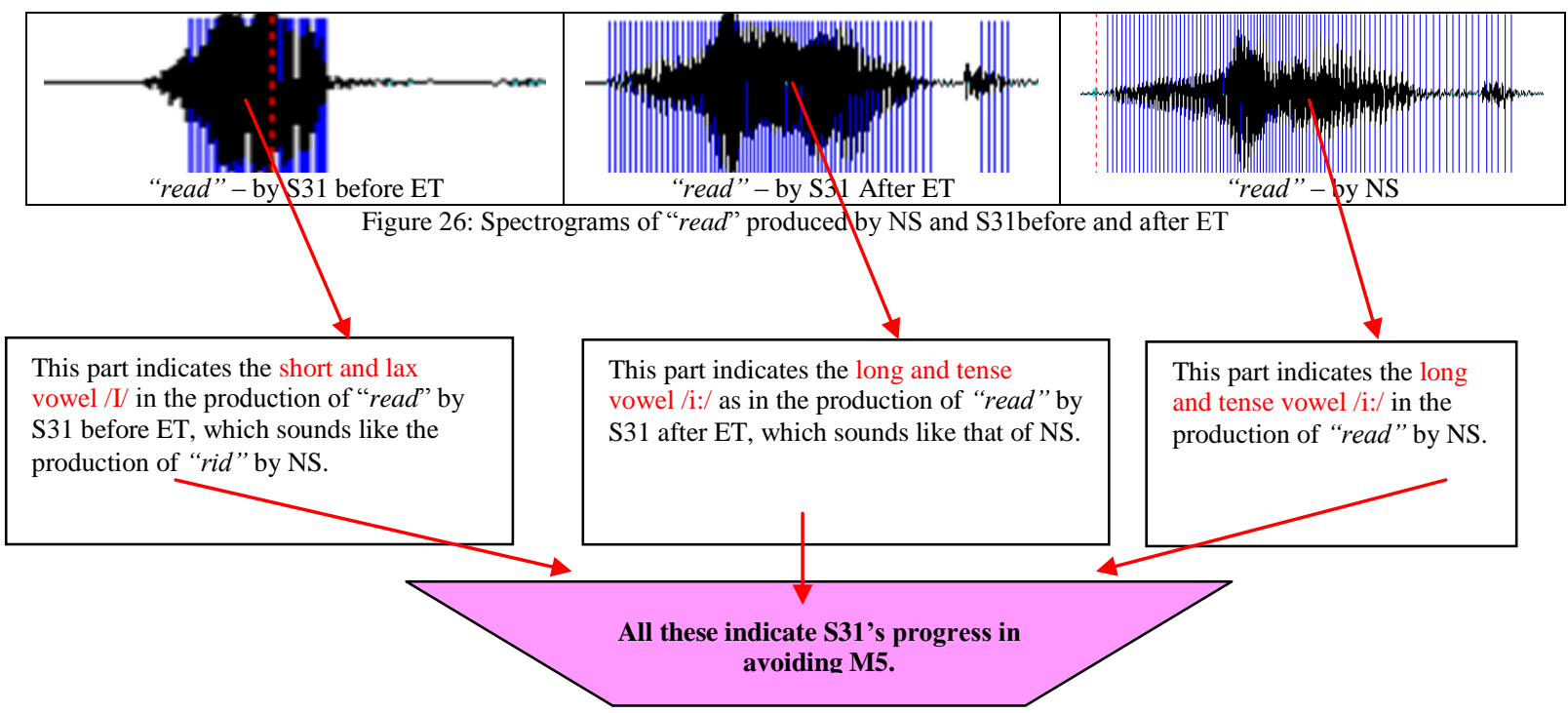


For Mistake 6 (Failing to differentiate between voiced and voiceless consonants) (see Figure 27)

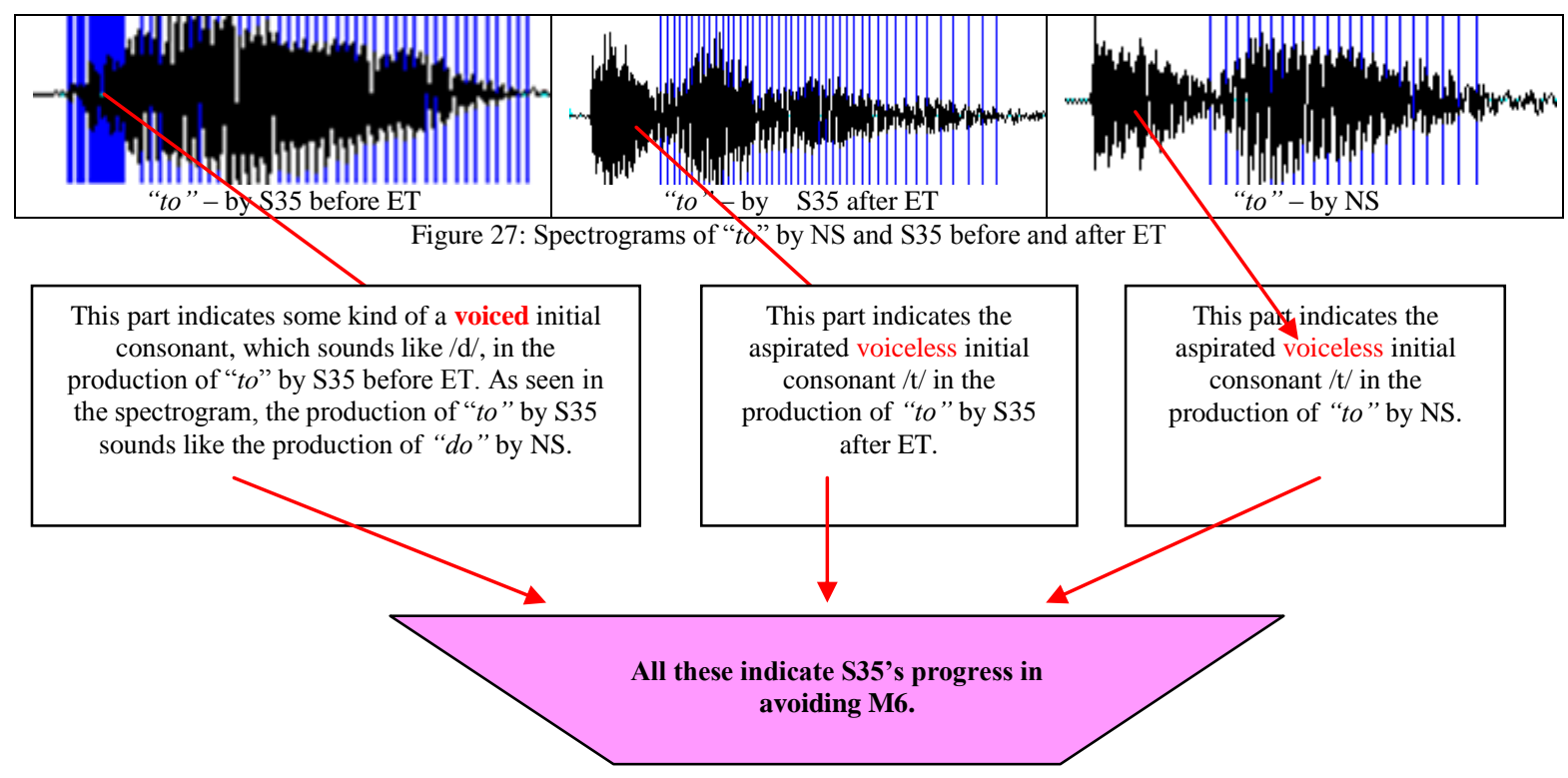

\section{CONCLUSION}

Minimal pairs bear great benefits in pronunciation teaching and learning which have long been of fruitful use. Nonetheless, the full use of these pairs has not yet been made in the setting of Hung Vuong University. Considered in the light of these assumptions, minimal pairs were selected as a means to solve pronunciation problems facing the institution's first-year students in acquiring English discrete sounds basically at word level. As observed and analyzed, both learners and teachers demonstrate high appreciation of the pedagogical effectiveness of minimal pairs when employed either as a teaching or learning tool within the extent to which English discrete sounds are concerned. As crucially, the experiment has considerably raised the students' awareness of the roles the pronunciation of English discrete sounds plays in oral communication; and as a result, these students are more motivated to make their own way into other aspects of English pronunciation with a more practical impetus either by themselves or with their teachers' support. After all, a new foundation has been laid for the sake of learners' further progress in English pronunciation via minimal pairs.

\section{REFERENCES}

[1] Asher, J. J. (1977). Learning another language through actions: The complete teacher's guidebook. Los Gatos, CA: Sky Oaks.

[2] Avery, P., and Ehrlich, S. (1995). Teaching American English Pronunciation. Oxford: Oxford University Press.

[3] Baker, A. (2006a). Tree or Three? - An Elementary Pronunciation Course. Third Edition. Cambridge: Cambridge University Press.

[4] Baker, A. (2006b). Ship or Sheep? - An Intermediate Pronunciation Course. Third Edition. Cambridge: Cambridge University Press.

[5] Baker, A., and Goldstein, S. (2008). Pronunciation Pairs - An Introduction to the Sounds of English. Second Edition. Cambridge: Cambridge University Press.

[6] Celce-Murcia, M., Brinton, D.M., and Goodwin, J.M. (1996). Teaching Pronunciation - A Reference for Teachers of English to Speakers of Other Languages. Cambridge: Cambridge University Press.

[7] Chomsky, N. (1972). Language and Mind. New York: Harcourt Brace Jovanovitch.

[8] Fromkin, V. \& Rodman, R. (1993). An Introduction to Language. Fifth Edition. United States: Holt, Rinehart and Winston, Inc.

[9] Hansen, D. (1995). A study of the effect of the acculturation model on second language acquisition. Ed. Eckman, P. Second Language Acquisition: Theory and Pedagogy. Mahwah, NJ: Lawrence Erlbaum Associates.

[10] Nilsen, D.L.F., and Nilsen, A.P. (1973). Pronunciation Contrasts in English. New York: Regents Publishing Company, Inc.

[11] Krashen, S.D., \& Terrell, T.D. (1983). The natural approach: Language acquisition in the classroom. London: Prentice Hall Europe.

[12] Rajadurai, J. (2001). An investigation of the effectiveness of teaching pronunciation to Malaysian TESL students. Forum, Vol 39 No 3, July - September. Retrieved on 14 October, 2004, from http://exchanges.state.gov/forum/vols/vol39/no3/p10.htm

[13] Richards, J.C., Platt, J., and Platt, H. (1993). Longman Dictionary of Language Teaching and Applied Linguistics. Third Edition. England: Longman Group UK Limited.

[14] Richards, J.C., Platt, J., \& Weber, H. (1987). Longman Dictionary of Applied Linguistics. London: Longman Publishing Group UK Limited.

[15] Tauroza, S. (1993). Recognizing words in continuous speech: How important are word-final consonants? ELT Journal, 47, 211-218. 
Luu Trong Tuan is currently an EFL teacher at National University of Ho Chi Minh City. He received his M.TESOL from Victoria University, Australia in 2004. Besides his focus on TESOL, his recent publications such as Language Transfer is Cultural Transfer between Communities, Social Sciences Review, No. 11, 2004, pp. 60-63; and Principles for Scientific Translation, Social Sciences Review, No. 8, 2004, pp. 63-67; and Building Vietnamese Medical Terminology via Language Contact, Australian Journal of Linguistics, Vol. 29, No. 3, September 2009, pp. 315-336 show his interest in language contact and translation areas. 